Verena Gassner

\title{
Elea/Velia, Terrasse I: Die spätarchaische Wohnbebauung und das so genannte Heiligtum des Poseidon Asphaleios
}

\author{
Einleitung
}

In der Topographie des griechischen Elea, rund $50 \mathrm{~km}$ südlich von Poseidonia an der tyrrhenischen Küste gelegen, nimmt der langgestreckte Hügelrücken, der vom mächtigen Massiv des Monte Gelbison zum Meer führt, eine besondere Rolle ein ${ }^{1}$ (Abb. 1). Sein westliches Ende, das heute von den Ruinen der mittelalterlichen Burg von Castellamare della Bruca beherrscht wird, trug in der Antike die Akropolis, während sich die Wohngebiete der Stadt an seinen südlichen Hängen erstreckten. Eine weiteres, wenngleich vermutlich weniger ausgedehntes Siedlungsgebiet wird auch für den im Norden liegenden Bereich angenommen, der jedoch noch kaum erforscht ist. Auf dem Höhenrücken selbst verläuft seit der Frühzeit der Stadt eine Befestigungsmauer, der Mauerzug A, der das Stadtgebiet in Art eines Diateichismas in eine Nord- und eine Südhälfte teilt ${ }^{2}$. Entlang dieser Mauer liegen insgesamt acht bekannte Heiligtümer bzw. Kultplätze, die mit wenigen Ausnahmen alle in der ersten Hälfte des 20. Jahrhunderts ergraben, aber in der Folge kaum erforscht wurden ${ }^{3}$.

Folgt man, von der Akropolis kommend, dem Hügelrücken landeinwärts, so steigt das Gelände nach dem markanten Einschnitt mit dem hellenistisch-römischen Theater deutlich an und erreicht nach einem kurzen Steilaufschwung eine relativ große, ebene Terrasse, die deutliche Spuren ihrer künstlichen Anlage zeigt. Östlich dieses terrassierten Platzes ist der Hang zunächst flach, dann etwas steiler und führt schließlich, schmäler werdend und zunehmend felsig, mit mäßiger Neigung zum Turm A 9, wo das Terrain abrupt zum Einschnitt der Porta Rosa abbricht. Dieser Bereich zwischen Akropolis und Porta Rosa wurde in der älteren Literatur als »terrazza $\mathrm{B}$ « bezeichnet, während er in der neuen Terminologie der italienischen Kollegen als »terrazza I« (Terrasse I) angesprochen wird ${ }^{4}$.

Aufgrund der exponierten Lage waren der Mauerzug A und die entlang von ihm liegenden Heiligtümer vermutlich immer zu sehen; sie sind jedenfalls bereits auf dem 1889 publizierten Plan von Wilhelm Schleuning eingezeichnet ${ }^{5}$. Ihre erste weitreichende archäologische Freilegung erfuhren sie 1926-1927 durch Amedeo Maiuri, der seine Arbeiten freilich nur in sehr zusammengefasster Form publizierte ${ }^{6}$. In der zweiten Hälfte

\footnotetext{
${ }^{1}$ Zur Stadtentwicklung allgemein vgl. G. Greco - F. Krinzinger (Hrsg.), Velia. Studi e ricerche (1994); F. Krinzinger - G. Tocco, s. v. Velia, in: EAA Suppl. 2 (1971-1994) V (1997) 967-974; F. Krinzinger - G. Tocco (Hrsg.), Neue Forschungen in Velia. Akten des Kongresses »La ricerca Archeologica a Velia« (Roma, 1.-2. Juli 1993), Velia-Studien I (1999); G. Greco (Hrsg.), Elea - Velia. Le nuove ricerche. Atti del Convegno di Studi, Napoli 14 dicembre 2001, Quaderni del Centro Studi Magna Grecia 1 (2003).

2 Die Bezeichnung der Mauerzüge geht zurück auf F. Krinzinger, Le mura urbane di Velia, in: CMGr 19, 1979 (1989) 355-362; ders., Die Stadtmauern von Elea, in: P. Leriche - H. Tréziny (Hrsg.), La fortification dans l'histoire du monde grec. Actes du colloque international »La fortification et sa place dans l'histoire politique, culturelle et sociale de monde grec«, Valbonne 1982 (1986) 121-124.

${ }^{3}$ Die Nummerierung der Kultplätze (von West nach Ost) erfolgte durch die Verf. anlässlich der Vermessungskampagne 2003; zu den Kulten vgl. zuletzt J. P. Morel, Observations sur les cultes de Velia, in: A. Hermary - H. Tréziny (Hrsg.), Les cultes de cités phocéennes. Actes du colloque international Aix-en-Provence/Marseille 4-5 juin 1999, Etudes massaliètes 6 (2000) 33-49; L. Vecchio, Le iscrizioni greche di Velia, Velia-Studien III (2003).

4 »Terrazza B« bei W. Schleuning, Velia in Lucanien, JdI 4, 1889, 179-194; in der Folge so auch bei P. C. Sestieri, Velia, FA 4 , 1949, 191-193 Nr. 1861. Zur neuen Terminologie vgl. Vecchio (Anm. 3) 30 Anm. 7.

5 Schleuning (Anm. 4).

${ }^{6}$ A. Maiuri, Velia: prima ricognizione ed esplorazione, Campagne della società Magna Grecia (1928) 14-29.
} 


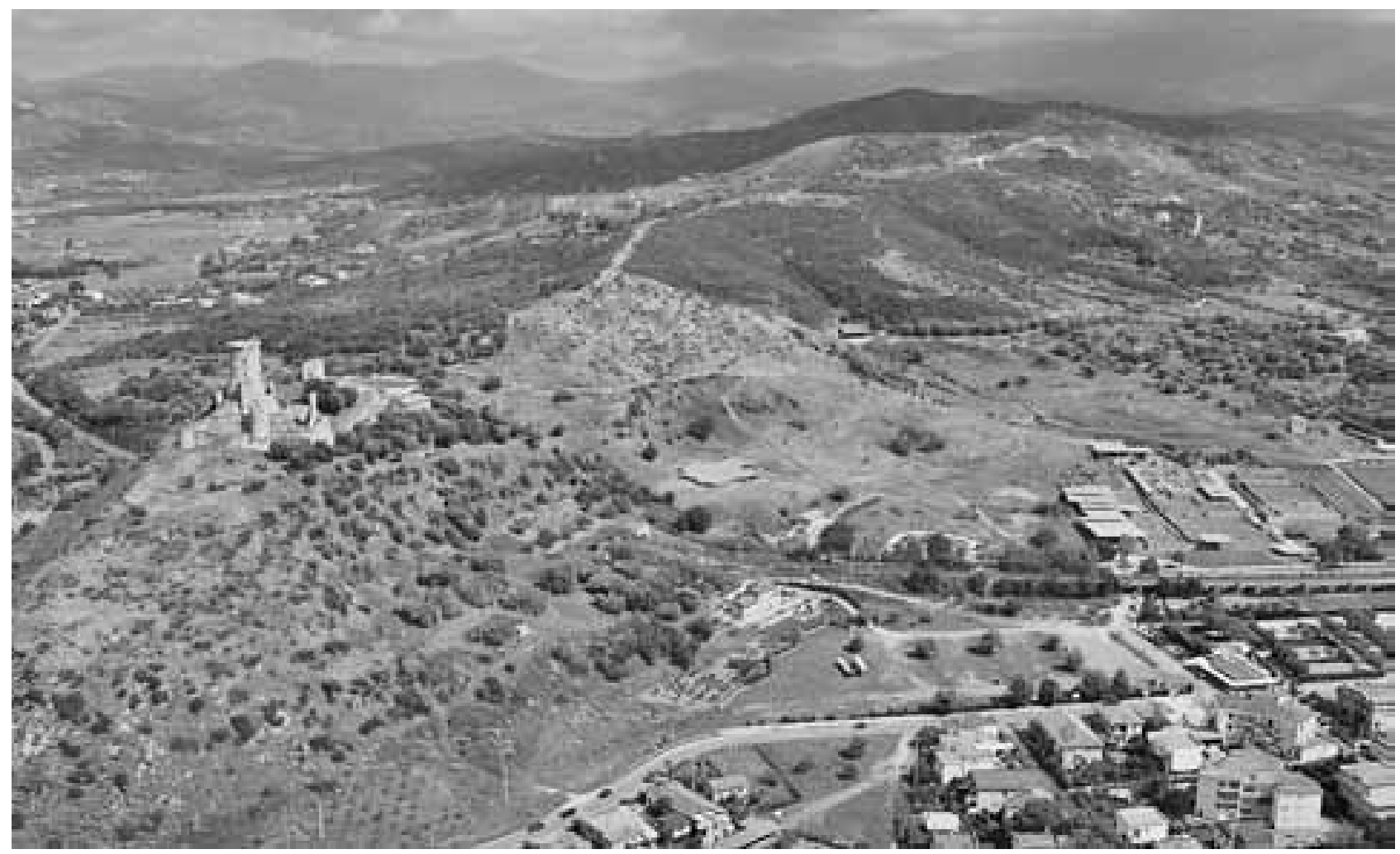

1 Das Stadtgebiet von Velia von Südwesten (Luftaufnahme 2002)

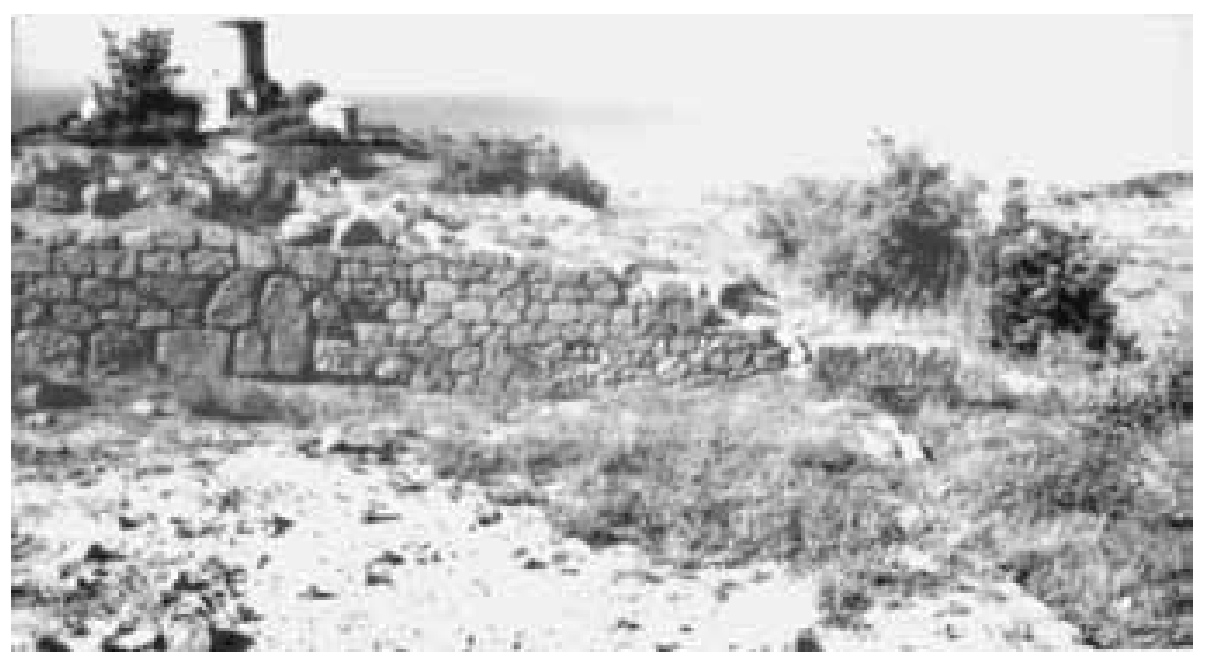

VELIA 2004
TErrass
Ansicht UMA 23
Anst 23

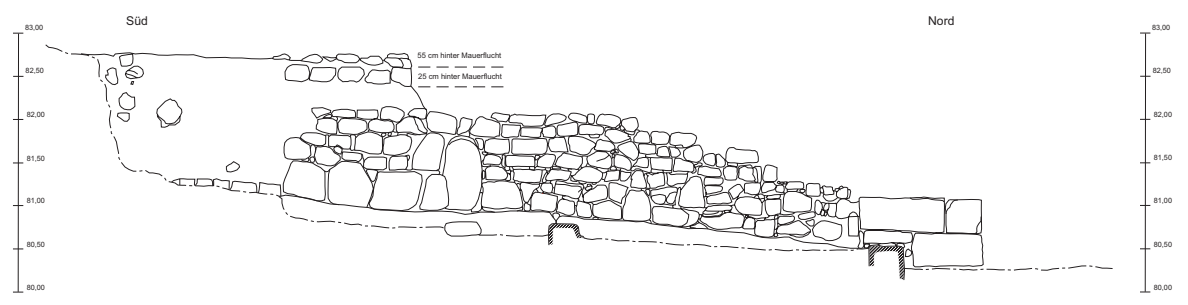

2 Polygonalmauer auf Terrasse I von Osten. Aufnahme aus den 70er Jahren sowie Zeichnung von J. Daum und F. Bittner (1978) 
des 20. Jahrhunderts waren es vor allem Pellegrino Sestieri und Mario Napoli, welche die Forschungen Maiuris fortsetzten ${ }^{7}$. So konnte die große Terrasse, welche die westlichen zwei Drittel des Hügels ausmacht, als ein um einen großen Hof angelegtes Heiligtum identifiziert werden, das aufgrund des Funds einer Stele für Poseidon Asphaleios als Heiligtum dieses Gottes bezeichnet wurde ${ }^{8}$. Ausführliche Berichte über die Grabungstätigkeit dieser Zeit fehlen fast vollständig.

Bei den Arbeiten von Mario Napoli im Jahr 1964 wurden auch auf Terrasse I Freilegungen vorge-

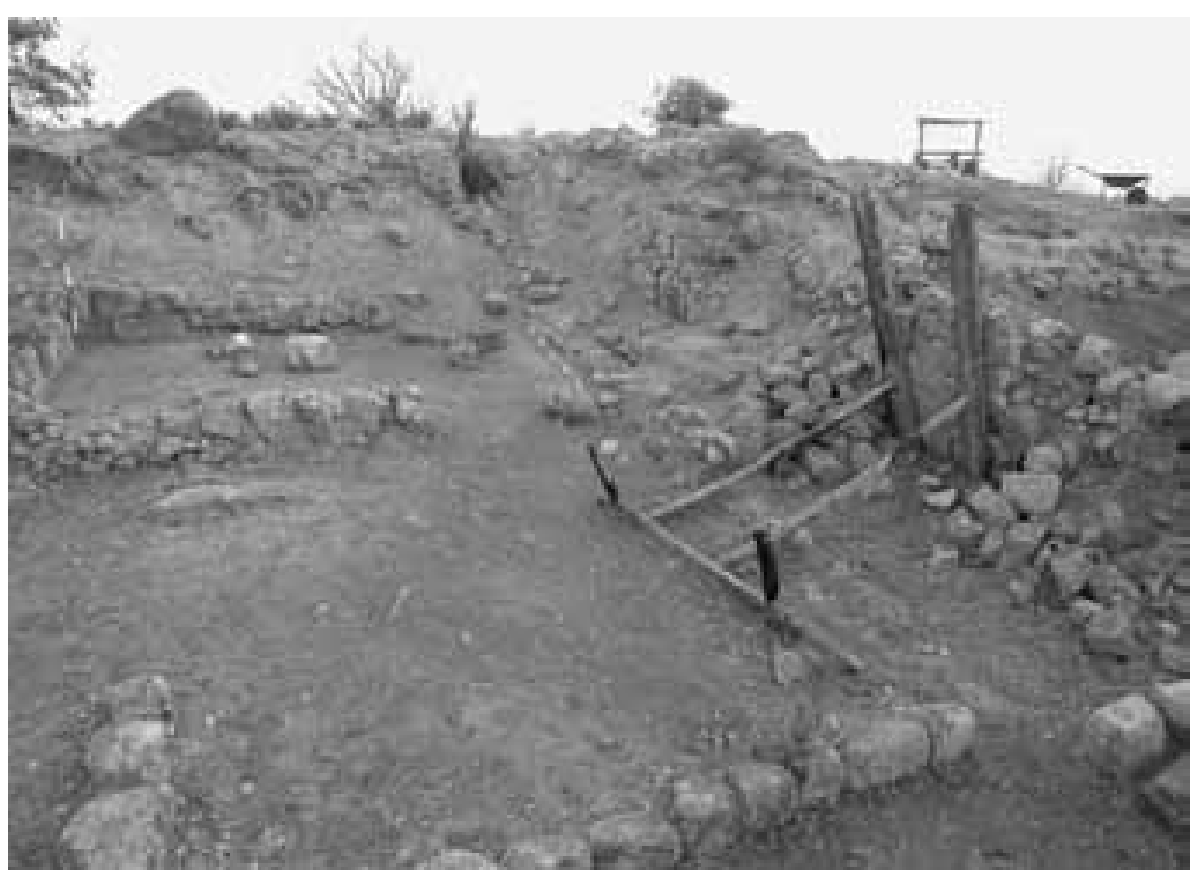

3 Ansicht der Polygonalmauer und des Antenhauses A.I. in geputztem Zustand bei Grabungsbeginn im Februar 2004 nommen, im Zuge derer östlich des Heiligtums des Poseidon Asphaleios im ansteigenden Hangbereich eine Mauer in schöner polygonaler Technik freigelegt wurde9 (Abb. 2). Die nächsten Grabungen datieren in das Jahr 1971, in dem Mario Napoli mit der Universität Salerno den Hang zwischen dem Heiligtum des Poseidon Asphaleios und der Polygonalmauer untersuchte ${ }^{10}$. Der Bereich östlich der Polygonalmauer fand hingegen im Januar 1978 erneut Aufmerksamkeit, als bei Restaurierungsarbeiten archaische Funde zutage kamen, darunter auch ein kleines Köpfchen einer weiblichen Terrakottafigur des sog. ionischen Typus. Die im Sommer desselben Jahres erfolgten zweiwöchigen Grabungen legten unmittelbar östlich der Polygonalmauer ein spätarchaisches Antenhaus mit drei Räumen sowie einer kleinen, nach Norden vorgelagerten Eingangshalle frei ${ }^{11}$. Der westlichste Raum (Nr. 4) wurde dabei von der Polygonalmauer in zwei Teile geteilt, sein westlicher Bereich nur durch einen kleinen, nicht zu Ende geführten Schnitt angegraben. Die Grabungsstelle wurde wegen der Bedeutung der aufgefundenen Situation für die Besucher sichtbar gehalten, was allerdings trotz versuchter Pölzungen der Polygonalmauer zu dem fast völligen Einsturz derselben führte (Abb. 3).

Eine neuerliche Untersuchung des Bereichs fand nach mehr als 25-jähriger Unterbrechung im Frühjahr 2004 statt. Für den Ausbau des Archäologischen Parks von Velia ist die Präsentation des Mauerzugs A sowie

\footnotetext{
7 Sestieri (Anm. 4) 191-193 Nr. 1861; M. Napoli, CMGr 3, 1964 (1965) 116-118; ders., La ricerca archeologica di Velia, PP 108-110, 1966, 209-211. Den besten Überblick über die Erforschung dieses Bereichs bietet derzeit die Zusammenfassung bei Vecchio (Anm. 3) 13 ff. Eine umfassende Studie zur Forschungsgeschichte von Velia ist durch ihn und L. Cicala in Arbeit.

${ }^{8}$ M. Guarducci, Divinità fauste nell'antica Velia, PP 21, 1966, 280-282; zusammenfassend Vecchio (Anm. 3) 50-53 mit der älteren Lit.

${ }^{9}$ Napoli (Anm. 7) Abb. 5.

${ }^{10}$ M. Napoli, L’attività archeologica nelle province di Avellino, Benevento e Salerno, in: CMGr 11, 1971 (1972) 381-402. Ein Plan des Quadrantensystems findet sich bei M. Napoli, Guida degli scavi di Velia (1972) 398 sowie bei C. Bencivenga, Resti di casa greca di età arcaica sull'acropoli di Velia, MEFRA 94, 1983, 417-448 Abb. 4, ist jedoch aufgrund des Abbildungsmaßstabs ohne Lupe kaum zu erkennen. Die Grabungsflächen zeichnen sich noch heute deutlich im Gelände ab und konnten bei der Kampagne im Februar 2004 teilweise neu dokumentiert werden, vgl. Beil. 1.

${ }^{11}$ Bencivenga (Anm. 10) mit der Neubewertung durch L. Cicala, L'edilizia domestica tardo arcaica di Elea, Quaderni del Centro Studi Magna Grecia 2 (2003) 119-130. Eine Abbildung des Grundrisses des Hauses findet sich bei Bencivenga (Anm. 10) Abb. 6. Eine Überprüfung dieses Plans in den Bereichen, in denen dies 2004 noch möglich war, zeigte, dass er - vor allem in der Westhälfte - Unstimmigkeiten von bis zu 0,20 m aufweist. Für unsere Beil. 2 wurde daher eine Zeichnung von J. Daum und F. Bittner verwendet, die im August 1978, also wenige Wochen nach den Grabungen im Juli desselben Jahres, im Maßstab 1:50 angefertigt worden war.
} 


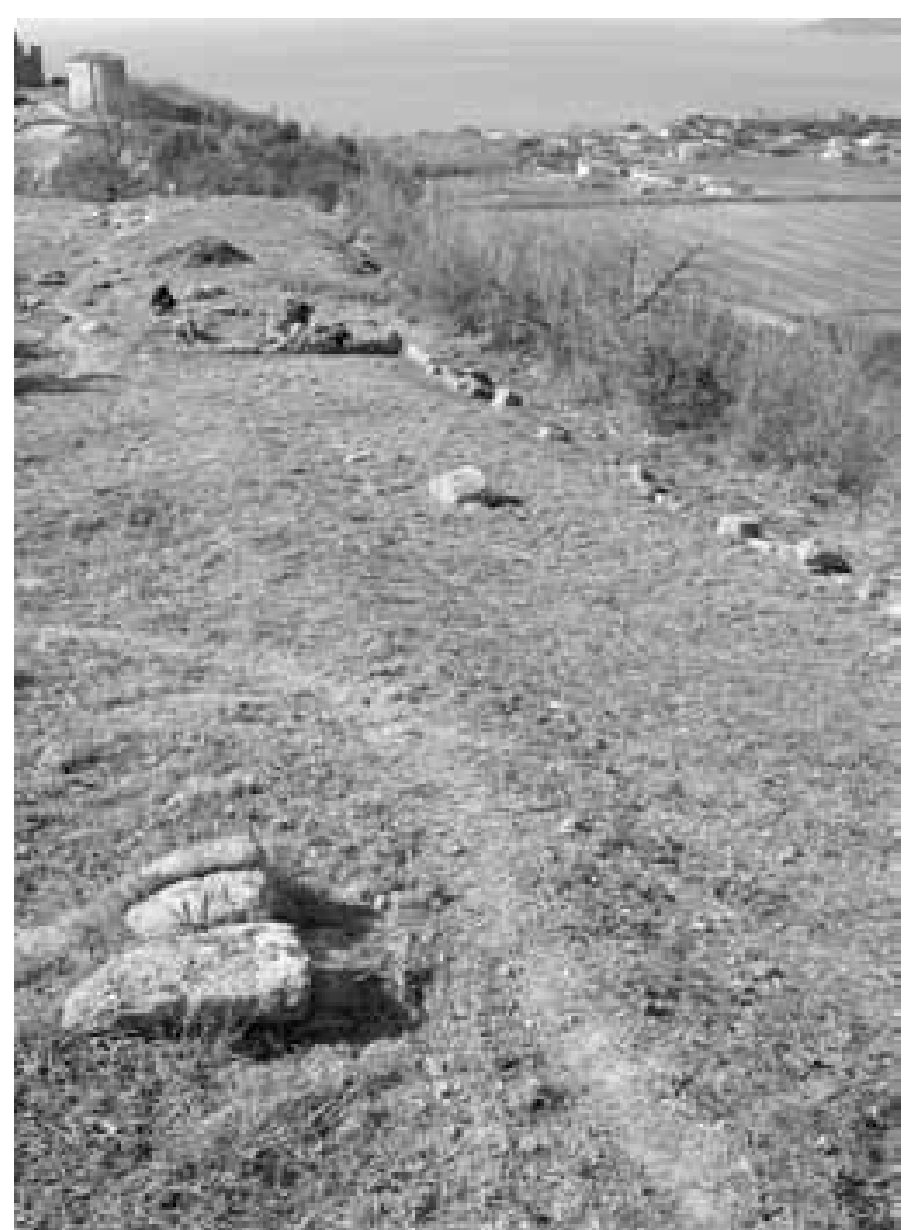

4 Die Stadtmauer UMA 17 zwischen dem Heiligtum des Poseidon Asphaleios und dem Antenhaus A.I. der entlang von ihm angelegten Heiligtümer für ein breites Publikum vorgesehen. Für die nötigen archäologischen Voruntersuchungen wurde von der Soprintendenza per i Beni Archeologici delle Province di Salerno, Benevento e Avellino das Institut für Klassische Archäologie der Universität Wien eingeladen, das im Zuge eines dreijährigen Forschungsprojekts bereits seit 2001 an verschiedenen Stellen dieses Teils der Befestigung Grabungen durchgeführt hatte ${ }^{12}$. Die Grabungen auf Terrasse $\mathrm{I}^{13}$ konzentrierten sich demnach zunächst vor allem auf die Stadtmauern, deren Verlauf und Entwicklung in diesem Bereich sie klären sollten. Für die Untersuchungen wurden zwei Bereiche ausgewählt: Zum einen wurde der östliche Rand des Westteils von Terrasse I untersucht, da hier der Verlauf der Stadtmauer unklar war (Beil. 1: Schnitte $3 / 04,5 / 04,7 / 04)$. Zum anderen wurde im Ostteil der Terrasse I der 1978 nur angeschnittene Bereich westlich der sog. Polygonalmauer untersucht, um zu überprüfen, ob diese - wie vermutet - mit der ältesten Phase der Stadtmauer identisch ist, und ob ihr Verlauf in späterer Zeit beibehalten wurde (Beil. 1: Schnitte 1-2/04, 6/04). Weiters wurde zwischen diesen beiden Bereichen ein Schnitt (Schnitt 4/04) über die Kurtine gelegt, um Aufschlüsse über ihren Innenaufbau zu erhalten.

\section{Der Verlauf der Stadtmauer ${ }^{14}$}

Das westliche Ende des Mauerzugs A ist im Bereich unmittelbar östlich des Einschnitts zwischen Akropolis und Terrasse I (A0) zu fassen. Neben dem in seinem heute sichtbaren Zustand der hellenistischen Bauperiode 3 angehörenden Mauerstück befindet sich ein kleiner Naiskos, der in der Forschung mit dem Kult der Kybele in Verbindung gebracht wird (Kultplatz 1) ${ }^{15}$. Die Fortsetzung der Mauer verschwindet bald im heute dicht verwachsenen Steilabfall nach Norden, wo sich aufgrund der Geländesituation kaum mehr nennenswerte

\footnotetext{
${ }^{12}$ Mein Dank für diese Einladung sowie die jahrelange großzügige Unterstützung geht an die Soprintendentin Dr. Giuliana Tocco sowie ihre Mitarbeiterinnen und Mitarbeiter, besonders Dr. Antonella Fiammenghi. Zu den Grabungen der letzten Jahre vgl. V. Gassner, Velia 2001 - Kurzbericht zu den Grabungen 2001, Forum Archaeologiae 21/XII/2001 (http://farch.net); V. Gassner A. Sokolicek - M. Trapichler, Velia 2002. Forschungen im Bereich des Castelluccio, Forum Archaeologiae. 25/X/2002 (http:// farch.net); dies., Die hellenistischen Stadtmauern von Elea. Die Ergebnisse der österreichischen Forschungen der Jahre 2000-2002, ÖJh 72, 2003, 67-95.

${ }^{13}$ Die Grabungen fanden in der Zeit vom 15. 2.-7. 3. 2004 statt. Teilnehmer/-innen waren neben der Berichterstatterin M. BruCalderon, D. Iro, K. Rebay, H. Schwaiger, A. von Miller (alle Universität Wien). Die Vermessungsarbeiten wurden von G. Augustin (Innsbruck) durchgeführt, die Zeichnungen und Pläne auf dieser Grundlage von D. Svoboda (Wien) umgesetzt. Die Soprintendenza per i Beni Archeologici delle Province di Salerno, Benevento e Avellino stellte für den Zeitraum im Durchschnitt sechs Arbeiter zur Verfügung. Von österreichischer Seite wird das Projekt durch den FWF sowie die Universität Wien unterstützt. Für die Restaurierung der Kleinfunde ist Karl Herold (ÖAI Wien) zu danken.

${ }^{14}$ In diesem Abschnitt über die Stadtmauer werden die Ergebnisse der Grabung 2004 kurz vorgestellt; die ausführliche Publikation der Befestigung wird in Band 4 der Velia-Studien durch V. Gassner, F. Krinzinger, A. Sokolicek und M. Trapichler erfolgen.

15 Zum Kult der Kybele in Elea vgl. zuletzt J. de La Genière, La Megale Meter a Velia?, in: Greco (Anm. 1) 63-68.
} 
Reste erhalten haben dürften. Wie die Schnitte 3/04, 5/04 und 7/04 zeigten, verspringt die Mauer am östlichen Ende des Heiligtums des Poseidon Asphaleios wieder nach Süden und erreicht so die obere Hangkante $^{16}$. Diese als UMA ${ }^{17} 17$ bezeichnete Mauer setzte sich auf einer Länge von insgesamt 35 m vom Heiligtum des Poseidon Asphaleios bis zum Bereich des Antenhauses A.I. fort, wobei in der Regel nur die Südseite klar zu erkennen, die Nordseite hingegen verstürzt ist (Abb. 4).

17 m östlich des Heiligtums wurde an einer Stelle,

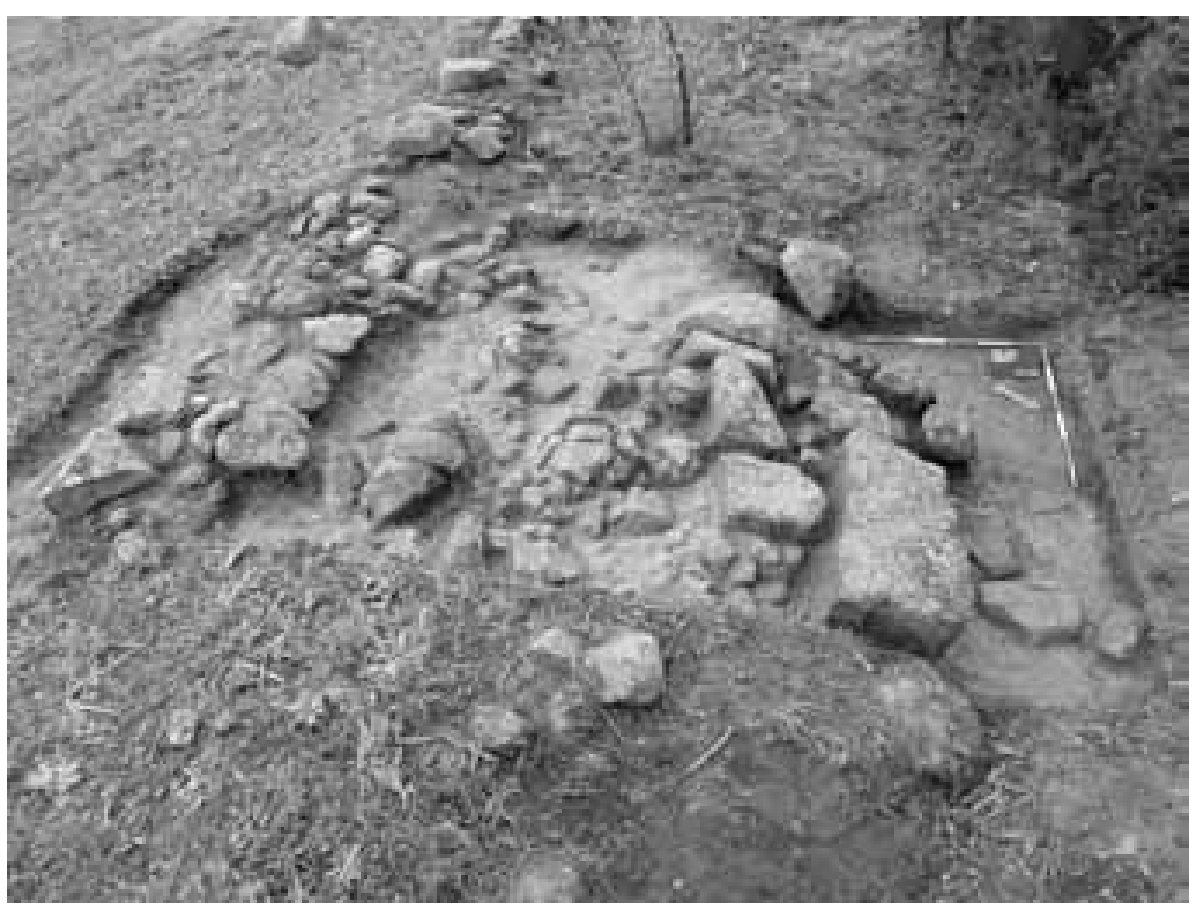

5 Schnitt 4/04 von Osten mit der Stadtmauer UMA 17 an der verstärkt Mauerquader an der Oberfläche zu beobachten waren, der Schnitt 4/04 angelegt ${ }^{18}$, um den inneren Aufbau der Mauer besser zu verstehen. Nach Abtragen des rezenten Humus wurden zwei Mauerschalen sichtbar, von denen die südliche aus kleineren, die nördliche aus großen Sandsteinquadern bestand (Abb. 5) ${ }^{19}$. Zwischen diesen beiden Mauerschalen fanden sich Reste des Emplektons, das aus kleineren, teilweise schon stark verwitterten Sandsteinen bestand. Unmittelbar unter der Kurtine folgt der gewachsene Boden in Form eines gelben, lehmigen Sands, der über dem anstehenden Fels liegt. Die Unterkante der südlichen Schale lag bei 80,14 bzw. 80,49 m absoluter Höhe (von Westen nach Osten ansteigend), jene der nördlichen bei 78,35 bzw. 78,68 m absoluter Höhe, sodass ein Höhenunterschied von fast $2 \mathrm{~m}$ bestand. Die Kurtine war demnach so an den abfallenden Nordhang angebaut, dass sie den Hang stützte, zugleich aber Teile des Emplektons eingespart werden konnten. Eine ähnliche Konstruktionstechnik ist vom Mauerzug B im Abschnitt nördlich von Turm B 1 bekannt ${ }^{20}$. Da sich die südliche und die nördliche Mauerschale deutlich durch die Größe der Steine unterscheiden, ist ferner zu überlegen, ob es sich bei den Sandsteinen der südlichen Schale nicht nur um eine Fundamentierung handelt, das eigentliche Bauniveau somit ursprünglich noch höher gelegen haben könnte ${ }^{21}$.

Die Mauer UMA 17 lässt sich im Gelände in unterschiedlichem Erhaltungszustand bis auf die Höhe der Polygonalmauer verfolgen (Beil. 1). Hier knickt die Mauer rechtwinkelig nach Süden um und führt zum Höhenrücken hinauf, wobei die östliche Mauerschale durch zwei große Konglomeratquader (UMA 26) angegeben wird (Beil. 2). Ihr weiterer Verlauf wurde erst durch Schnitt 1/04 besser erfasst: Er zeigte, dass die Mauer hier wieder einen Höhenunterschied von fast 1,5 $\mathrm{m}$ zu überwinden hatte und nach Erreichen des Kamms erneut in Ost-West-Richtung umschwenkte. Ihr weiterer Verlauf ist im felsigen Bereich des Höhenrückens relativ gut bis zum Turm A 9 zu verfolgen, da sie sich zumeist klar in der Felsformation abzeichnet, wobei meist nur die Südkante durch Mauerwerk aus kleineren Sandsteinen akzentuiert wird ${ }^{22}$.

Im Bereich westlich der Polygonalmauer waren vor Grabungsbeginn einige schlecht erhaltene, oft nur aus einer Steinlage bestehende Mauern sichtbar, für die aufgrund ihrer Lage an der Stadtmauer anzunehmen war,

\footnotetext{
${ }^{16} \mathrm{Zu}$ den genannten Schnitten vgl. u. »Das Heiligtum des Poseidon Asphaleios im Westteil der Terrasse I«.

${ }^{17}$ Unita Muraria des Mauerzugs A.

${ }^{18}$ Maße: 4,50 m (N-S) $\times 3 \mathrm{~m}(\mathrm{~W}-\mathrm{O})$.

${ }_{19}$ Größe der Steine der südlichen Mauerschale ca. 0,45 × 0,38 × 0,08 m, der nördlichen 1,10 × 0,50 × 0,40 m (US 403/04).

${ }^{20}$ Gassner - Sokolicek - Trapichler (Anm. 12:2003) 70 f. Abb. 5.

${ }^{21}$ Eine ähnliche kleinteilige Fundamentierung der Stadtmauer UMA 17 findet sich auch in Schnitt 7/04, vgl. dazu u.

${ }^{22}$ Gassner (Anm. 12:2001); Gassner - Sokolicek - Trapichler (Anm. 12:2003) $70 \mathrm{ff}$.
} 


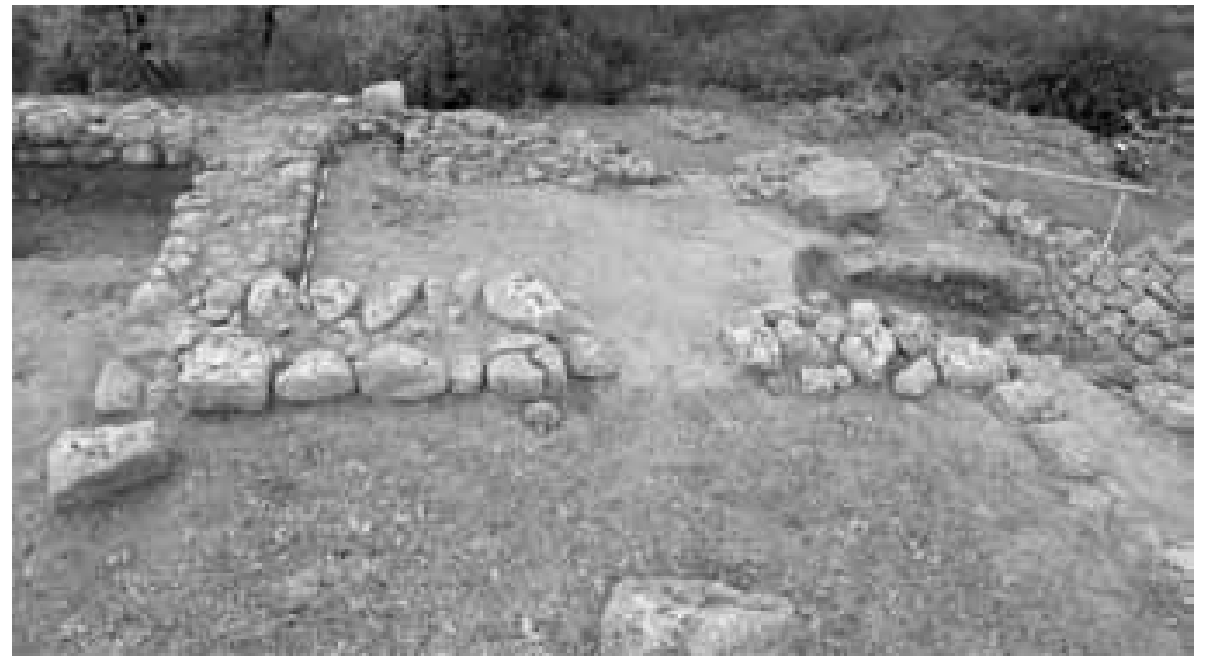

6 Blick von Süden auf Schnitt 1/04 und 2/04 (l.) bei Grabungsbeginn. Am rechten Bildrand vor der Mauer ist der alte, nicht fertiggestellte Schnitt des Jahres 1978 zu erkennen.

dass sie auch funktional mit ihr in Verbindung zu sehen seien (Abb. 6). In der südlichen Verlängerung der Polygonalmauer, aber auf einem deutlich höheren Niveau ${ }^{23}$ verliefen die Mauern UMA 24 und 25a, von denen UMA 24 aus schönen Sandsteinquadern, UMA 25a hingegen nur aus einer Steinlage bestand. Mit Letztgenannter sind UMA 25b und c verbunden, die gemeinsam mit UMA 17 ein Rechteck von insgesamt 6,3 × 2,2 m einschließen. 3,1 m weiter westlich war eine weitere, in Nord-Süd-Richtung verlaufende Steinreihe (UMA 28) zu sehen.

Von den beiden in diesem Bereich angelegten Schnitten erbrachte Schnitt 2/04 keine nennenswerten Ergebnisse $^{24}$, Schnitt 1/04 hingegen die erhofften Erkenntnisse zum Aufbau der Stadtmauer (Beil. 2). Diese ist zunächst als UMA 17 an der Nordkante des Schnitts zu erkennen, wobei die nördliche Mauerschale aus großen Quaderblöcken fehlt. Erhalten haben sich hingegen unterschiedlich gestaltete Elemente des Emplektons, bei denen sich kleinteiliges Steinmaterial (US 105/04, 107/04 und 121/04) mit größeren Sandsteinquadern (US 114/04, 106/04 und UMA 27) abwechselt, die vermutlich der internen Mauerverstärkung dienten. Nach dem Knick Richtung Süden sind die Konglomeratblöcke von UMA 26 eindeutig der Stadtmauer zuzuweisen, im ansteigenden Abschnitt ist das Gelände bis unter das Niveau der Stadtmauer abgetragen, große Blöcke fehlen. Erst nach Erreichen des eigentlichen Hügelkamms finden wir wieder Reste der westlichen Mauerschale (UMA 24 bzw. UMA 25a).

Stratigraphisch kann die Situation aufgrund der rezenten Eingriffe nur teilweise erfasst werden (Beil. 3: Südprofil, Beil. 4: Nordprofil). An die sehr massiv gebaute Mauer UMA $17^{25}$ schloss nach Süden zu im gesamten Schnittbereich eine Lage aus kleinteiligen Sandsteinen, vereinzelt auch aus Dachziegelfragmenten an (US 112/04, 116/04), deren Gesamtausdehnung größer als der Schnittbereich ist. Über ihr folgten künstlich angeschüttete, lehmige, fundleere Sande (US 109/04, 108/04), auf denen die erwähnten Mauern UMA 25a-c sowie UMA 24 errichtet wurden. Beim Bau der Stadtmauer hatte sich durch den Kammverlauf die Notwendigkeit eines weiteren Mauerversprungs ergeben. Dabei musste in einer schwierigen Ecksituation über eine kurze Strecke ein relativ großer Höhenunterschied überwunden werden: Man errichtete im Norden eine von der sonst in Periode 3 üblichen Bauweise abweichende, sehr massive Terrassierungsmauer (UMA 17) und verwendete für den Bereich der Nord-Süd verlaufenden Mauer die - offensichtlich noch sichtbare - Polygonalmauer als willkommene Fundamentierung. Der so entstandene Zwickel wurde hinterfüllt, wobei zunächst die Steinlage US 112/04 als Drainagierung und darüber die sandigen Aufschüttungen 109/04 und 108/04 aufgebracht wurden. Auf der erreichten ebenen Fläche lassen sich weitere Aufbauten vorstellen, die sich allerdings in UMA 25a-c nur noch in den untersten Fundamentlagen erhalten haben.

\footnotetext{
${ }^{23}$ UK UMA 24 bei 82,17 m, UMA 25 bei 81,89 m absoluter Höhe.

${ }^{24}$ Die Grabungen wurden nach einem Abtiefen von rund 0,60 $\mathrm{m}$ im fundleeren, gelben Sand (US 202/04) eingestellt (UK bei 80,80 $\mathrm{m}$ absoluter $\mathrm{H}$ ), nachdem Bohrungen auch für die nächsten 0,80 m keine Änderung der stratigraphischen Abfolge erwarten ließen. Erst nach Abschluss des Schnitts 1/04 und der Auswertung der Geländevermessung wurde klar, dass wir hier mit einem deutlichen Geländesprung nach Westen zu rechnen haben, die zu vermutenden älteren Mauern daher noch viel tiefer hätten liegen müssen.

${ }_{25}$ Mit US 114/04, 105/04, 106/04, 107/04, 121/04.
} 
Die chronologische $\mathrm{Zu}-$ ordnung der eben geschilderten Befestigungsmauer zur hellenistischen Periode 3 erfolgt vor allem anhand der Bautechnik und der teilweisen Verwendung von Konglomeratblöcken. Aus den Anschüttungsschichten in Schnitt 1/04 wurden keine datierenden Funde geborgen, die darunter liegende Verbauung gehört bereits dem 5. Jahrhundert v. Chr. an. Als überraschendes Ergebnis der Untersuchungen ist festzuhalten, dass unter dieser hellenistischen Stadtmauer keine Vorgängermauer nachzuweisen war. Es ist daher nötig, zu überlegen, ob im 5. Jahrhundert v. Chr. im Bereich der Terrasse I bis zum Turm A 9 überhaupt eine Mauer existierte, zumal bis jetzt kein einziges Teilstück der Mauer hier mit Sicherheit der Periode I zugewiesen werden konnte ${ }^{26}$. Andererseits haben bereits die Arbeiten im Bereich von Turm A 9 gezeigt, dass die älteren Strukturen bei Errichtung der hellenistischen Neubauten äußerst gründlich abgetragen wurden, sodass ihre Spuren oft nur in schwer zu erkennenden Abarbeitungen im anstehenden Fels erhalten geblieben sind $^{27}$. In diesem Zusam-

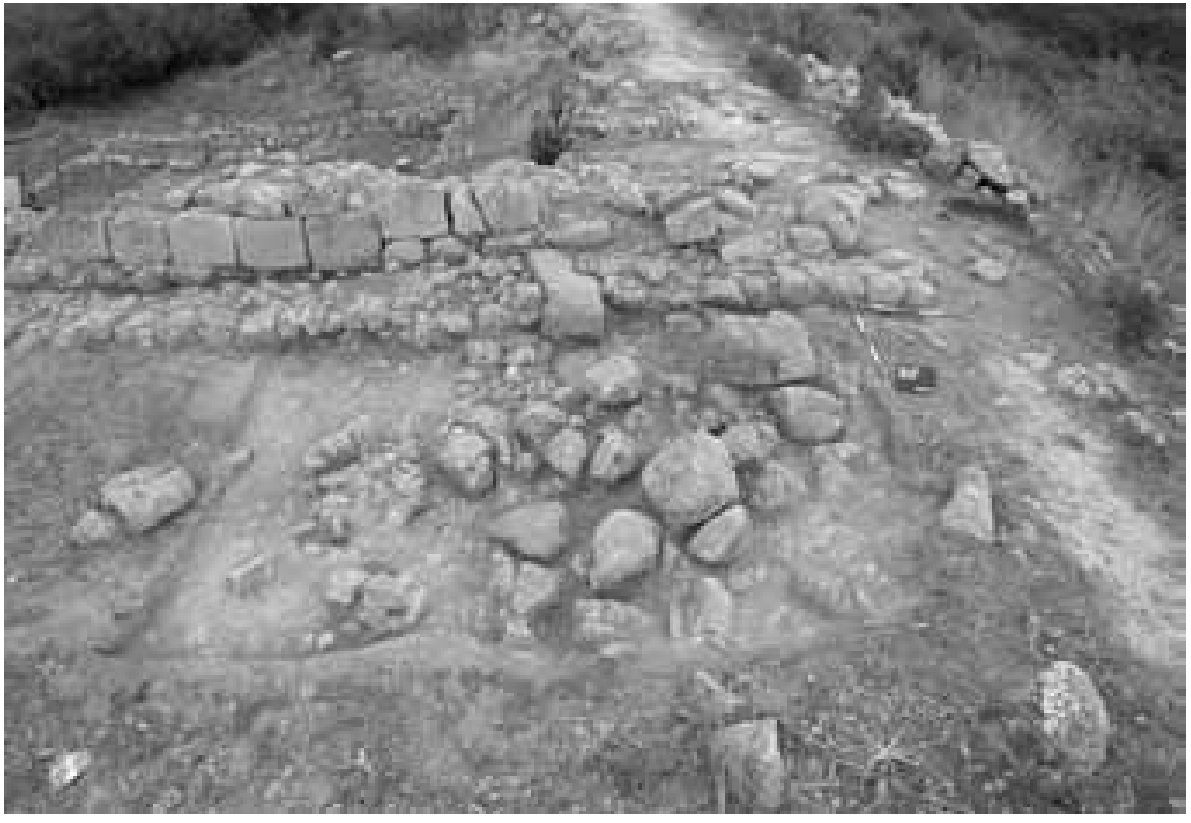

7 Schnitt 6/04 Ost (von Westen aufgenommen, der Nordpfeil liegt falsch)

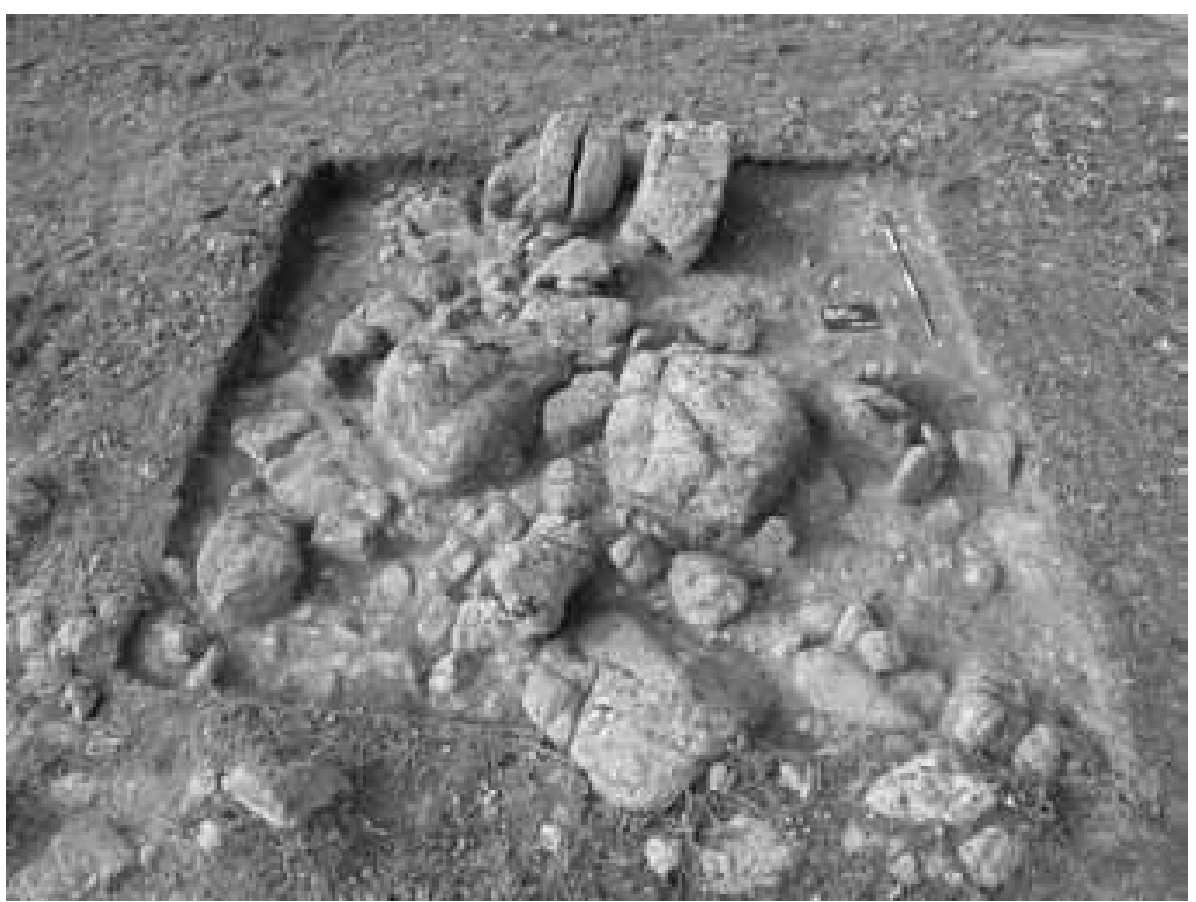

8 Schnitt 6/04 West menhang sind die Schnitte 6/04 Ost und West von Interesse: Sie wurden im östlichen Bereich der Terrasse I an zwei Stellen angelegt, an denen im anstehenden Fels Bearbeitungsspuren in Kombination mit einer Ansammlung von Steinquadern beobachtet werden konnten (Beil. 1). Schnitt 6/04 Ost (Abb. 7. 9) schließt direkt an UMA 25a an und wurde 1971 bereits durch einen Schnitt erfasst ${ }^{28}$. Im Gegensatz zu dem von lehmigen Sand gekennzeichneten Nordteil wird seine südliche Hälfte durch den mit größeren Felsbrocken durchsetzten anstehenden Fels eingenom-

\footnotetext{
${ }^{26}$ Ich danke A. Sokolicek für die Diskussion dieser Problematik, auf die er in der Endpublikation noch ausführlich eingehen wird.

${ }^{27}$ Gassner - Sokolicek - Trapichler (Anm. 12:2003) 72 und $80 \mathrm{ff}$.

${ }^{28}$ Maße 6/04 Ost: 4 × 3 m $(\mathrm{N}-\mathrm{S} / \mathrm{O}-\mathrm{W})$.
} 


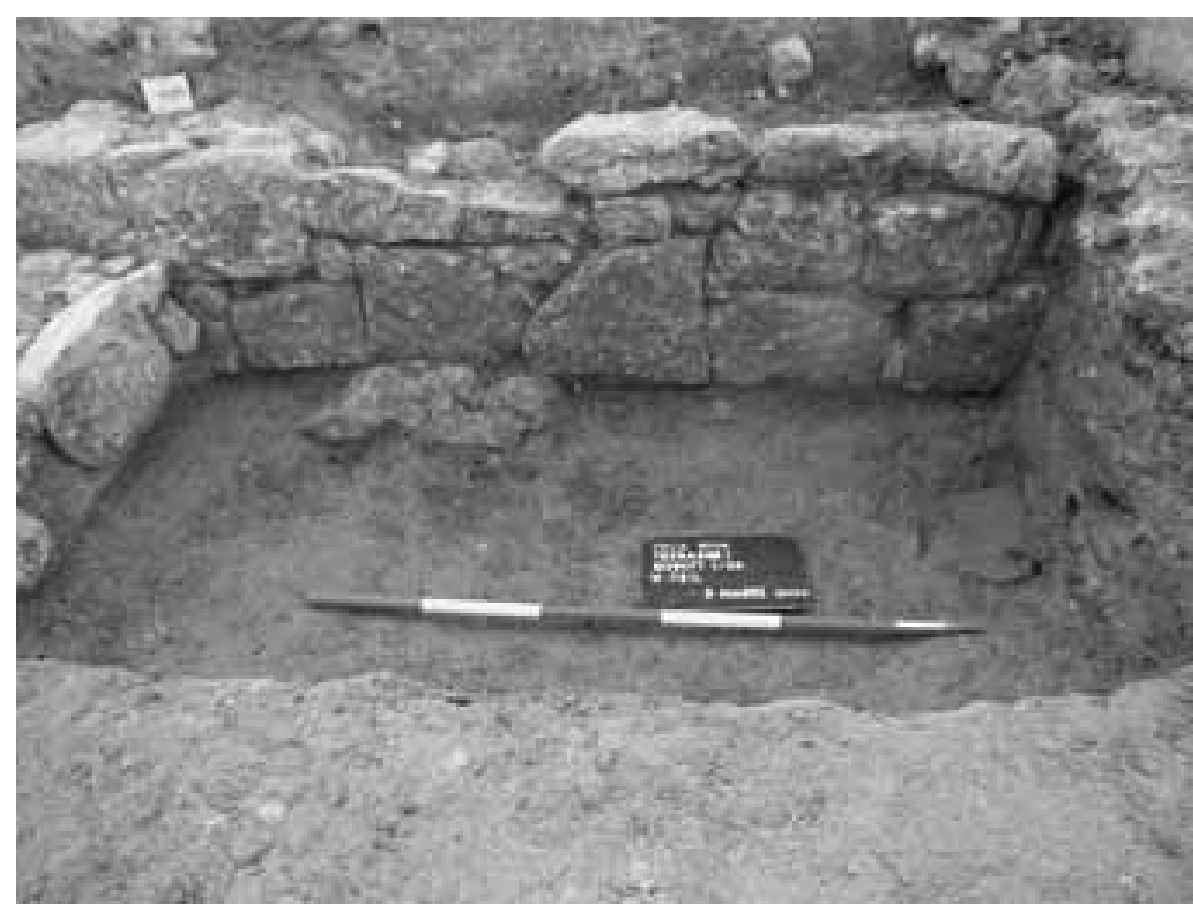

9 Die Mauer 131/04 von Norden. Am linken Bildrand ist der Ansatz der Mauer 133/04 zu erkennen, die mit ihrer hier sichtbaren Westseite in den gelben Lehmziegelversturz 137/04 hineingesetzt wurde. men, der deutliche Spuren künstlicher Bearbeitung erkennen lässt. Hervorzuheben ist ein unregelmäßiger, großer Sandsteinblock mit bearbeiteter Nordkante (US 605/04), der die nördliche Abschlusskante angeben könnte, während der südliche Abschluss wohl im Block 602/04 zu sehen ist, der an der Südseite am deutlichsten von allen Steinen eine geglättete Kante aufweist. Die Distanz zwischen 602/04 und 605/04 beträgt 2,40 m und hat damit ein für die Stadtmauer der Periode 2 charakteristisches Maß. Eine weitere auffallende Stelle ist der längliche Stein $603 / 04$, der als integrierter Teil von UMA 25a etwas aus dieser nach Westen vor-

kragt. Der Abstand zwischen seiner Nordkante und der Südkante des Blocks 602/04 misst 1,80 m und ergäbe damit die übliche Breite der Kurtine der Periode 1. Diese Zahlenspielereien werden allerdings durch die Situation im nicht ganz 7 m entfernten Schnitt 6/04 West (Abb. 8) relativiert, der ebenfalls bereits von den Grabungen des Jahres 1971 betroffen war. Reste der Mauer lassen sich hier am deutlichsten am Nordrand des Schnitts erkennen (UMA 75), während der übrige Schnittbereich von deutlich höher anstehendem, aber nicht eindeutig künstlich bearbeitetem Fels eingenommen wird. Die durch die Nordseite von UMA 75 vorgegebenen Orientierung fluchtet nun nicht exakt mit jener des Schnitts 6/04 Ost. Die Frage, ob sich in diesen nur noch schwer zu definierenden Spuren im Fels Reste einer älteren Kurtine, am ehesten der Periode 2, erhalten haben, die dann nicht im Abhang, sondern mitten auf dem Höhenrücken verlaufen wäre, lässt sich somit nicht eindeutig beantworten.

\section{Die spätarchaische Wohnbebauung im Ostteil der Terrasse I}

Bereits 1978 war durch Clara Bencivenga am Ostrand der Terrasse I das nach Norden orientierte Antenhaus A.I. freigelegt worden ${ }^{29}$. Es bestand aus dem 4,60 × 4,00 m großen Raum 1 mit einer nach Norden vorgelagerter Vorhalle (Raum 2), an den in einer oder zwei Umbauphase(n) ein Raum im Süden (Raum 3) und einer im Westen (Raum 4) angebaut worden waren (Beil. 2). Raum 3 liegt auf einem rund 0,30 m höheren Niveau als Raum 1, weswegen ihn Bencivenga auch für den spätesten Anbau hielt. Seine Ost- und Südmauer zeigen auch bei dem heutigen schlechten Erhaltungszustand noch zwei Lagen relativ großer, schöner Sandsteinblöcke (Abb. 3), die ein Hinweis darauf sein könnten, dass dieser Raum - wie von der Akropolis gut bekannt - in den Hang eingetieft war, da die mit dem feuchten Erdmaterial in Kontakt stehenden Wände in der Regel aus Stein errichtet wurden, während die vorderen, freistehenden Wände nur einen niedrigen Steinsockel und ein Aufgehendes aus Lehmziegeln aufwiesen ${ }^{30}$. Raum 4 wird durch die später errichtete Polygonalmauer in zwei

\footnotetext{
${ }^{29}$ Bencivenga (Anm. 10); eine Neubewertung des Befunds zuletzt bei Cicala (Anm. 11) 119-130.

${ }^{30}$ So schon angedeutet bei Bencivenga (Anm. 10) $424 \mathrm{f}$. und in der Bildunterschrift zu Abb. 2. Zur Technik vgl. F. Krinzinger, Intorno alla pianta di Velia, in: Greco - Krinzinger (Anm. 1) 20.
} 
10 Schnitt 1/04 Ostprofil: Ansicht der Mauer UMA 23 West sowie im unteren Bereich der Mauer 151/04 aus kleineren Steinen und der Flyschsteinlage 142/04 im linken Bildbereich

11 Schnitt 1/04 Ostteil. Blick von Süden auf die Steinlage 136/04

12 Tiefschnitt im östlichen Bereich von Schnitt 1/04. Blick auf 133/04 von Osten
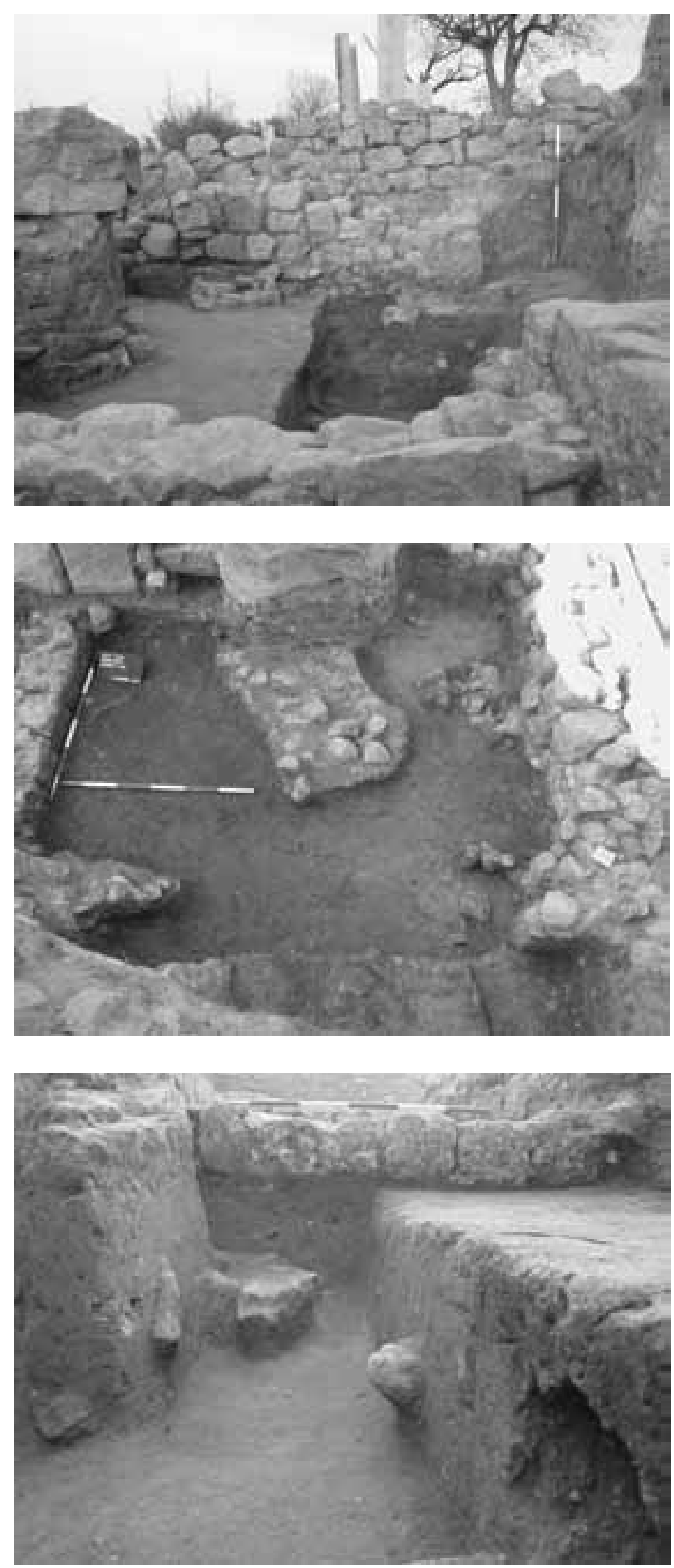
Teile zerschnitten; im westlichen Bereich wurde von Clara Bencivenga ein kleiner Schnitt mit den Maßen 2,30 × 1,70 m angelegt, aber nicht zu Ende geführt ${ }^{31}$. Seine Konturen zeichneten sich 2004 nach dem Putzen deutlich im Gelände ab (Abb. 6). Bereits zu Beginn der Grabung des Jahres 1978 waren die oberen Schichten des Bereichs stark gestört gewesen, sodass - vor allem an der exponierten, von der natürlichen Erosion betroffenen Nordseite - der anstehende Fels freilag. Die darunter liegenden lehmig-sandigen Straten wiesen auf zwei Bauphasen des Hauses hin, wobei beide, feinchronologisch schwer zu unterscheiden, in die spätarchaische Zeit gehören. Die Grabungen im Februar 2004 konzentrierten sich mit Schnitt 1/04 auf den Bereich westlich der Polygonalmauer, in dem der Raum 4 zu erwarten war.

\section{Das Antenhaus A.I.}

Das unterste in Schnitt 1/04 angetroffene Stratum ist ein brauner, lehmiger Sand, der im Ostteil als US 140/04, im Westteil als US 146/0432 bezeichnet wird (Beil. 4: Tiefschnitt). Er enthielt kleine Sandsteinsplitter und einige größere, teilweise verbrannte Sandsteine, die ebenso wie der Fund einer Knickrandschale deutlich machen, dass es sich bei ihm nicht um den natürlich anstehenden Boden handelt, der an keiner Stelle des Schnitts erreicht wurde. Von seiner nach Westen hin mäßig abfallenden Oberkante wurde im Ostteil eine Grube (US 150/04 IF) abgetieft, die nur zu einem kleinen Teil in der Schnittverkleinerung ergraben wurde, z. T. auch unter der späteren Polygonalmauer liegt, sodass ihre Ausdehnung nicht vollständig zu klären war ${ }^{33}$. Diese Vertiefung war mit Wechsellagen von dunklem, vor allem im Nordprofil stark aschigem Material und Sand (US 147-149/04) verfüllt, sonst aber fundleer ${ }^{34}$.

Im Ostteil entstand über diesem lehmigen Sand ein dunkles Lehmstratum (US 144/04), das ebenfalls vereinzelte Sandsteinbrocken enthielt. Es ist vor allem im Westprofil unter der Mauer 133/04 zu erkennen und dünnt westlich von dieser sowie nach Norden zu stark aus, was mit der ursprünglichen Geländeneigung in Verbindung stehen könnte (Beil. 3: Südprofil). Auf seinem Niveau wurde die Ost-West orientierte Mauer 131/04 errichtet; sie hat sich in zwei, ganz im Westen sogar in drei Lagen erhalten (Abb. 9). Ihre gegen den Schnitt hin gerichtete Nordseite besteht aus einer Reihe großer ${ }^{35}$, unregelmäßiger, aber schön behauener Sandsteine, die als pseudopolygonal bezeichnet werden könnten; sie hat Parallelen in zeitgleichen Beispielen auf der Akropolis ${ }^{36}$. Da eine südliche Mauerschale fehlt, entsteht der Eindruck einer gegen den Hang gesetzten Terrassierungsmauer. Dies würde angesichts der topographischen Verhältnisse durchaus Sinn machen, doch ist theoretisch auch möglich, dass die südliche Mauerschale noch unter dem Südprofil des Schnitts liegt. Das westliche Ende dieser Mauer wurde nicht ergraben, da es von der späteren Mauer 120/04 überbaut wird. Im Osten bricht die Mauer im Bereich des alten Schnitts des Jahres 1978 ab und lässt sich in diesem kaum mehr verfolgen. Planimetrisch könnte sie ihre Fortsetzung in einem völlig zersetzten Sandstein US 141/04 haben, der genau in der Verlängerung der Mauer 131/04 und auf einem der Unterkante von 131/04 entsprechenden Niveau von 80,30/80,40 m absoluter Höhe festgestellt wurde.

Eventuell könnte noch eine weitere Mauer zu dieser ersten Bautätigkeit gehören: Im mittleren Bereich der Polygonalmauer UMA 23 West lässt sich beobachten, dass die Steinreihen unterhalb eines Niveaus von 80,65 m absoluter Höhe aus deutlich kleineren, unregelmäßigen Sandsteinen bestehen (Abb. 10; Beil. 3), die durch eine nicht immer klar zu erkennende Horizontalfuge vom oberen Mauerteil getrennt werden (Mauer 151/04). Ihre Unterkante verläuft etwa bis zu dem erwähnten Sandsteinrest 141/04 relativ eben bei einem

\footnotetext{
${ }^{31}$ Vgl. Bencivenga (Anm. 10) 419 Anm. 7.

32 Die tiefste, nur in der Schnittverkleinerung ergrabene Stelle liegt bei 79,80 m absoluter Höhe. Die unterschiedliche US-Bezeichnung desselben Stratums beruht auf der grabungstechnisch bedingten Trennung der beiden Bereiche östlich und westlich der Mauer 133/04.

${ }^{33}$ Im Nordprofil des Tiefschnitts ist sie auf einer Länge von ca. 1,50 m zu sehen. Ihre Erstreckung nach Süden kann anhand des Ostprofils unter der Polygonalmauer rekonstruiert werden, wo sich vielleicht ihre Südkante andeutet, allerdings aufgrund eines Wasseraustritts im Südprofil nicht mit Sicherheit festzustellen ist.

34 Die Wechsellagen sind erkennbar in Abb. 10 im Tiefschnitt unter der Mauer 151/04.

${ }_{35}$ Maximale Blockgröße etwa 0,35 × 0,40 m.

${ }^{36}$ Etwa in einer Mauer von Gebäude VI, vgl. Cicala (Anm. 11) Taf. 9, 2; vgl. ebenda 198 ff. zuletzt zusammenfassend zur Technik.
} 
Niveau von 80,30 m absoluter Höhe, steigt südlich von diesem aber rasch und deutlich bis zu einer absoluten Höhe von fast 80,80 m an. Es bleibt unklar, ob dies der ursprünglichen Hangneigung entspricht, etwa im Sinn eines in den Hang gebauten Raumes, oder in anderer Weise das Südende der Mauer 151/04 markiert. Das nördliche Ende der Mauer 151/04 wird von einer 0,50 m nach Westen vorspringenden, annähernd quadratischen Lage aus Flysch- und Sandsteinen sowie Dachziegeln eleatischer Produktion gebildet (US 142/04), über und nördlich von welcher sofort die größeren Steine von UMA 23 West anschließen. Die Funktion dieses Sockels 142/04 ist unklar. Unmittelbar westlich von ihm wurde eine im Zuge der Grabung abgetragene, längsrechteckige Steinlage (US 136/04) in Nord-Süd-Orientierung angetroffen, die aus kleinen Sandsteinen bestand und aufgrund der Begrenzung des Phänomens als Rollierung, etwa einer Herdstelle, anzusprechen ist (Abb. 11). Damit ergeben sich für diese erste Bauphase zwei Mauern (131/04 und 151/04), die möglicherweise die Ecke eines Raumes bildeten, der mit Raum 1 des Antenhauses vergleichbar wäre; die Mauern trugen über den Steinsockeln Wände aus Lehmziegeln. Dieses sehr hypothetisch zu rekonstruierende Gebäude muss in seinem westlichen Teil relativ bald eingestürzt sein. Zeugnis dafür ist ein nur im Westteil festzustellender massiver Lehmziegelversturz (US 139/04) mit einer Mächtigkeit von 0,30-0,40 m, dessen Unterkante nach Westen abfällt (Beil. 4: Nordprofil).

Bei den in der Folge einsetzenden Restrukturierungsmaßnahmen wurde an die unterste Steinlage der Mauer 131/04 im rechten Winkel die Nord-Süd orientierte Mauer 133/04 angesetzt (Abb. 12). Sie besteht aus zwei Reihen etwa 0,30 × 0,20 m großer, unregelmäßig behauener Sandsteine, die nur in einer Lage erhalten sind. Auffallend ist, dass die Steine der Ostschale viel kleiner sind und in oder gegen den Lehmziegelversturz gesetzt wurden. Diese Mauer 133/04 stellt die Westmauer des Raumes 4 dar, der somit ebenfalls etwas in den Boden eingetieft worden war. Sie war aufgrund einiger an der Nordseite unter der Stadtmauer sichtbarer Steine bereits von Clara Bencivenga erschlossen worden ${ }^{37}$. Die südliche und die nördliche Begrenzung von Raum 4 wurden im Jahr 1978 im Teil östlich der Polygonalmauer ergraben; die südliche ist heute aber durch den Versturz der Polygonalmauer im Gelände nicht mehr eindeutig zu lokalisieren. Westlich der Polygonalmauer war die Fortsetzung dieser Mauer teilweise unterhalb der hellenistischen Mauer UMA 25b, teilweise außerhalb des Schnitts zu vermuten. Von ihr fanden sich aufgrund der Störung durch den Schnitt des Jahres 1978 keine eindeutig zuweisbaren Reste. Einziges Anzeichen könnten die bei einem Niveau von etwa 80,30 bis 80,40 m absoluter Höhe gefundenen Reste von Lehmziegeln und von völlig durch Wasser zersetzten Sandsteinen (US 135/04) sein, die unmittelbar am Südprofil lagen und in ihrer Ausrichtung der Südmauer von Raum 4 entsprachen (Abb. 13).

Die Zerstörung oder Aufgabe dieses Raumes 4 ist im Ostteil durch ein dunkelbraunes, lehmiges Stratum charakterisiert (US 137/04, Beil. 4: Nordprofil), das nach vereinzelt zu erkennenden Lehmziegeln als Lehmziegelversturz zu interpretieren ist. In ihm fanden sich Fragmente attischer Glanztonware sowie das Randfragment einer chiotischen Amphore des Typus Knigge C 2, weiters Reste von Dachziegeln, die auf eine entsprechende Deckung von Raum 4 hinweisen.

\section{Das Gebäude in polygonaler Technik}

Nach der vollständigen Zerstörung des Antenhauses wurde - nach Aussage der Funde sehr rasch - mit der Errichtung eines neuen Gebäudes begonnen, dessen Dimensionen nur unvollständig wiedergewonnen werden konnten. Auch seine Funktion bleibt weitgehend unklar. Seine Westbegrenzung besteht aus der Mauer 120/04, die über dem Lehmziegelversturz 137/04 sowie über die ältere Mauer 131/04 gebaut wurde. Es handelt sich um eine zweischalige Mauer aus größeren, nicht ganz regelmäßigen Sandsteinblöcken ${ }^{38}$, zu der ein im Osten vorspringendes Fundament aus kleineren, unregelmäßigen Sandsteinen (US 138/04) gehört (Abb. 14). Ihre Gesamtbreite beträgt 0,70 m; sie ist damit fast doppelt so breit wie die Steinsockel des Antenhauses A.I.

\footnotetext{
${ }^{37}$ Benivenga (Anm. 10) Abb. 6 Nr. 17. Sie ist heute jedoch nicht mehr zu sehen. Die planimetrischen Angaben des alten Plans lassen sich in der Orientierung nicht ganz mit der neu ergrabenen Mauer in Übereinstimmung bringen, daher stimmt auch die von C. Bencivenga angegebene Richtung dieses Mauerstücks nicht exakt mit jener von Mauer 133/04 überein; vgl. zu diesen Übereinstimmungsproblemen o. Anm. 11. Es ist dennoch von einer Zusammengehörigkeit beider Mauerstücke auszugehen.

${ }^{38}$ Durchschnittliche Maße 0,30/0,35 × 0,25 × 0,20 m.
} 


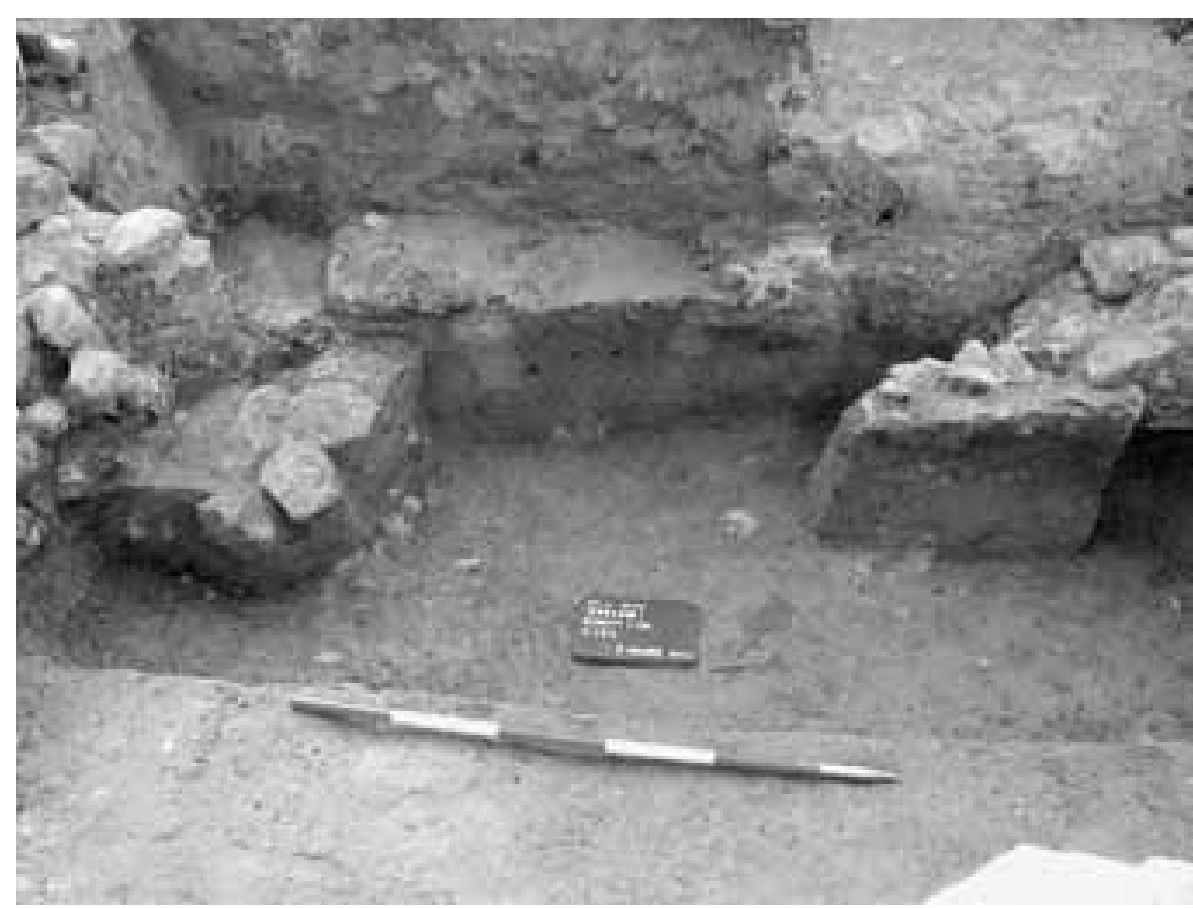

13 Blick von Norden auf die Lehmziegellage 135/04 an der südlichen Schnittkante sowie links davon - auf die Sandsteine 141/04 (u.) und den Mauerstumpf 132/04 (o.)
Ihr Nutzungsniveau von 80,60 m absoluter Höhe entspricht etwa der Unterkante von UMA 23, die auch nach der Mauertechnik als Ostwand desselben Gebäudes anzusprechen sein dürfte. Der schlechte Erhaltungszustand verursacht freilich einige Schwierigkeiten bei ihrer Interpretation. Bei der Auffindung war die Polygonalmauer ursprünglich für eine von Osten gegen den Hang gesetzte Terrassierungsmauer gehalten worden $^{39}$. Diese Annahme entbehrte freilich angesichts des nach Westen abfallenden Hangs von Anfang an der Logik. Zum Zeitpunkt der Grabungen 2004 war die Mauer an der Ostseite be-

reits weitgehend zerstört (Abb. 3); die Analyse der Mauer konzentrierte sich deshalb vor allem auf die Westseite sowie den südlichen, noch erhaltenen Teil der Ostseite. Dabei zeigte sich, dass die heute insgesamt etwa $1,20 \mathrm{~m}$ breite ${ }^{40}$ Mauer ursprünglich möglicherweise aus zwei Mauern bestand, die mit einer Längsfuge nebeneinander errichtet wurden. Auch die Errichtung einer Mauer, an die in einem zweiten Arbeitsschritt eine zweite Mauer angebaut wurde, ist nicht auszuschließen. Die beiden Mauerteile werden in der Folge als UMA 23 Ost und UMA 23 West bezeichnet (Beil. 2).

Für die Beurteilung der insgesamt rund 8 m langen UMA 23 Ost sind wir weitgehend auf alte Photographien und Zeichnungen angewiesen ${ }^{41}$. Die östliche Polygonalmauer bestand demnach in ihrem nördlichen Teil auf einer Länge von rund $4 \mathrm{~m}$ aus mittelgroßen, polygonal geschnittenen Sandsteinen ${ }^{42}$, die weitgehend in durchgehenden Lagen versetzt worden waren (Abb. 2). Die unterste Reihe besteht aus Blöcken, die deutlich größer sind als die folgenden Lagen, von denen sich noch fünf bis sechs erhalten haben. Nach Süden zu folgen nach einem die Höhe von vier Lagen aufweisenden, monolithartigen Block ${ }^{43}$ vier weitere Blöcke, deren Höhe jener von drei Lagen im Nordteil entspricht. Die darüber liegenden Steinblöcke entsprechen jenen des Nordteils. An diese großen Blöcke schließen nach Aussage der Zeichnung von Johannes Daum noch fünf kleine Sandsteine (oder Ziegel?) an, die heute nicht mehr zu sehen sind. Die Bedeutung dieses Wechsels in der Bautechnik ist nicht eindeutig zu klären. Eine mögliche Begründung wäre, dass die großen Steine dort eingesetzt wurden, wo die Mauer gegen den Hang gesetzt wurde und gleichsam die Funktion einer Terrassierung übernahm, während die kleineren Steine im Norden den freistehenden Mauerteil charakterisieren. Allerdings bleibt damit die Frage nach der Funktion der nach Süden anschließenden kleinen Steine, die nur auf der Zeichnung von Daum dokumentiert sind, unbeantwortet.

Die westliche Polygonalmauer ist noch schwieriger zu fassen, da von ihr vor dem Jahr 2004 keine Ansichten dokumentiert worden waren, sie aber durch den nicht beendeten Schnitt des Jahres 1978 schwer

\footnotetext{
${ }^{39}$ Bencivenga (Anm. 10) 419 Anm. 7.

${ }^{40}$ Genaue Maße sind aufgrund des heutigen Erhaltungszustands sowie der starken Neigung der Mauer in dem bereits 1964 freigelegten Ostteil nicht zu erhalten.

41 Vgl. o. Anm. 11.

${ }^{42}$ Durchschnittliche Größe 0,35 × 0,15/0,20 m.

${ }^{43}$ Höhe von $0,85 \mathrm{~m}$.
} 
in Mitleidenschaft gezogen wurde. Sie besteht aus unregelmäßigen Sandsteinen, die kaum polygonalen Charakter aufweisen (Beil. 3; Abb. 10). Im Bereich des alten Schnitts war sie in ihrem oberen Teil stark zerstört. Obwohl aus den älteren Grabungen im östlichen Bereich keine Hinweise zur stratigraphischen Relation des Hauses A.I. zur Polygonalmauer hervorgehen, lässt sich aufgrund des annähernd gleichen Niveaus der Unterkanten beider Polygonalmauern mit jener von US 120/04 (bei 80,60-80,80 m absoluter Höhe) sowie der ähnlichen Bauweise und

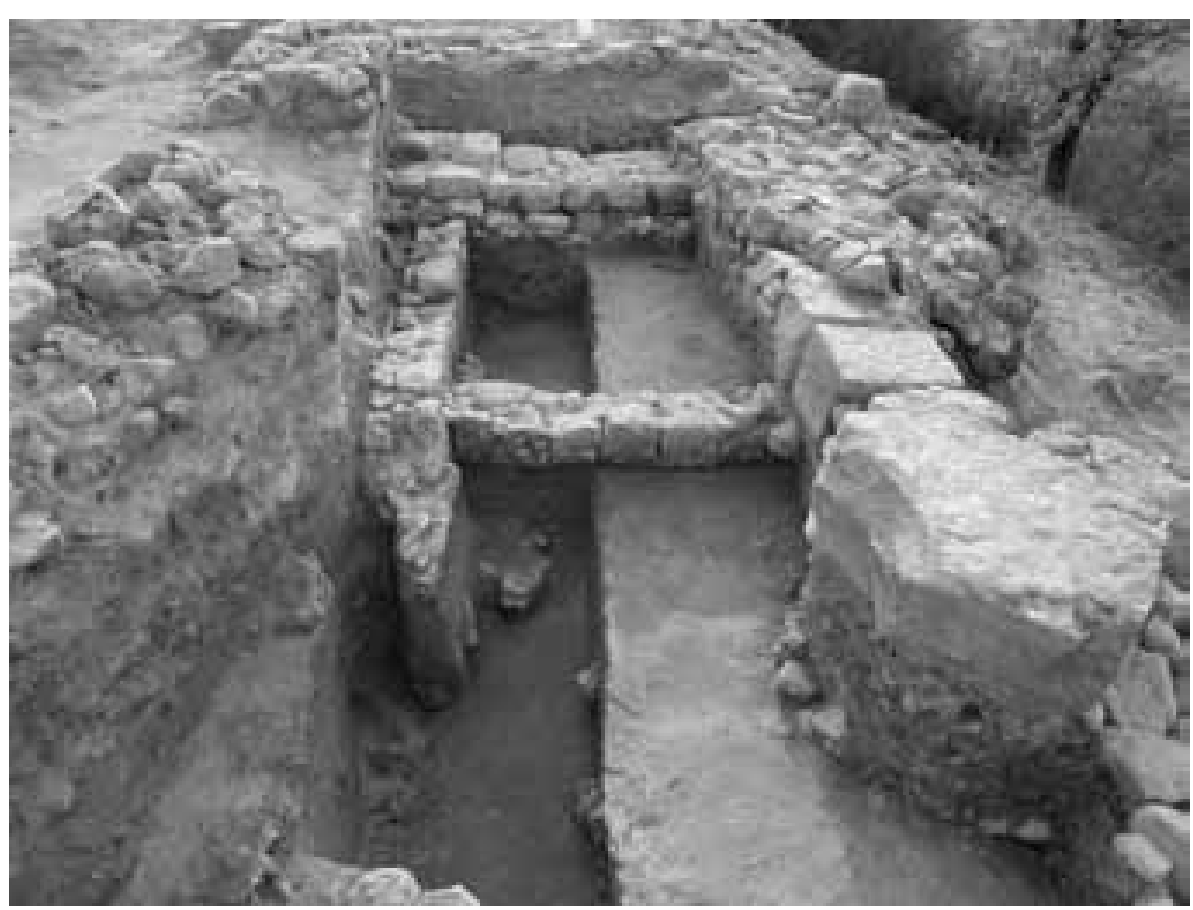

14 Schnitt 1/04 von Osten. Im Hintergrund die Mauer 120/04 mit dem Fundament 138/04 Orientierung eine gleichzeitige Errichtung dieser Mauern vermuten. Wir haben es in dieser Phase demnach mit einem Gebäude zu tun, das aus knapp 5 m auseinanderliegenden, Nord-Süd verlaufenden Mauern bestand. Der nördliche und der südliche Abschluss fehlen ${ }^{44}$.

Auffallend ist, dass sowohl UMA 23 als auch die Mauer 120/04 im Vergleich zu den 0,35-0,40 m starken Mauern der älteren Häuser deutlich breiter sind. Die zu dieser Phase zugehörigen Zerstörungsschichten lassen außerdem vermuten, dass auch diese Mauern zumindest teilweise Aufgehendes aus Lehmziegeln getragen haben. Dafür sprechen auch eine massive Ausgleichsschicht aus graugelbem Lehm (119/04) direkt auf der Mauerkrone von 120/0445 sowie massive Reste von Lehm an der nördlichen (US 110/04) und südlichen (US 117/04) Kante von UMA 23 West. Die im gesamten Schnittbereich festgestellte Zerstörungsschicht US 122/04 bestand aus einer durchschnittlich 0,20 m mächtigen, von Süden nach Norden abfallenden, rötlichen Lehmschicht, in der sich deutlich die Reste von Lehmziegeln abzeichneten; sie enthielt außerdem einige rot verbrannte Sandsteinfragmente, sodass sich Brandeinwirkung zumindest in bedingtem Rahmen als Zerstörungsursache nicht ausschließen lässt. Als Deckung des Hauses kann anhand mehrerer Dachziegelfragmente ein Ziegeldach vermutet werden.

Die im Stratum 122/04 in großen Mengen angetroffene Gefäßkeramik entspricht nach einer ersten Durchsicht dem bereits aus den älteren Grabungen bekannten Spektrum von Haushaltsgeschirr. Weiters zu erwähnen sind einige qualitätsvolle Fragmente attischer schwarzfiguriger Keramik sowie ein kleiner Pferdekopf aus Terrakotta und einige bronzene Pfeilspitzen. Insgesamt spricht nichts gegen die Zugehörigkeit der Funde zu Häusern einer relativ wohlhabenden Bevölkerungsschicht, doch wären einige Funde auch in kultischem Zusammenhang gut zu erklären. Der zeitliche Rahmen kann nicht enger als auf das erste Viertel des 5. Jahrhunderts v. Chr. eingegrenzt werden ${ }^{46}$.

${ }^{44}$ Möglicherweise könnte die südliche Quermauer in einem Mauerstumpf gesehen werden, der in den Plänen von C. Bencivenga und J. Daum auf gleicher Höhe mit der Südwand von Raum 4 eingezeichnet ist, jedoch im rechten Winkel zu UMA 23 steht. Er war 2004 im Befund nicht mehr zu lokalisieren und kann ebenso gut mit der Nachnutzung des Bereichs in Verbindung gebracht werden.

45 Ähnliche Phänomene wurden auch bei den Stadtmauergrabungen 1997 im Bereich des Mauerzugs G festgestellt, vgl. dazu V. Gassner - A. Sokolicek, Die Befestigungsanlagen von Velia. Vorbericht zu den Grabungen in der Unterstadt 1997-1999, ÖJh 69, 2000, $101 \mathrm{ff}$.

${ }^{46}$ Vgl. dazu bereits Bencivenga (Anm. 10) 427 ff. und Cicala (Anm. 11) 129 f. 
Die Bebauungsgeschichte des Ostrands von Terrasse I lässt sich folgendermaßen zusammenfassen: Im letzten Drittel des 6. Jahrhunderts v. Chr. wurde - vermutlich gleichzeitig mit den Räumen 1 und 2 des Antenhauses A.I. ${ }^{47}$ - in einem Abstand von wenig mehr als $2 \mathrm{~m}$ nach Westen ein weiteres Haus errichtet, von dem allerdings nur die in den Hang gesetzte südliche Rückwand sowie möglicherweise die Ostwand zu fassen sind. Nach der partiellen Zerstörung dieses Gebäudes wurde der Bereich für einen Anbau an das Antenhaus A.I genutzt und der Raum 4 errichtet. Da Raum 4 mit den sich dabei ergebenden Maßen von rund 5,20 × 3,50 m auffallend groß wäre, könnte er unter Weiterverwendung der Mauer 151/04 auch in einen östlichen und einen westlichen Teil geteilt worden sein, wobei die dabei entstandenen kleinen Räume 3,20 × 2,00 m im Osten (Raum 4a) und 3,10 × 2,60 m im Westen (Raum 4b) gemessen hätten, was den vom Südhang der Akropolis bekannten Raumdimensionen besser entspräche. Eine Reihe von Beobachtungen macht klar, dass es sich bei dem Antenhaus A.I. nicht um ein einzelnes, isoliertes Haus handelte, sondern dass in spätarchaischer Zeit mit einer zumindest lockeren Bebauung der Terrasse I mit Wohnhäusern zu rechnen ist. Neben dem neu entdeckten Haus der ersten Phase im Westen von A.I. sind hier weitere Mauern anzuführen, die im Erdprofil östlich des Antenhauses beobachtet und eingemessen werden konnten und auf eine Fortsetzung der Bebauung deuten. Ferner zu erwähnen ist auch eine nur in Resten erhaltene Mauerecke aus unregelmäßigen, kleinen Sandsteinen, die am äußersten Westrand von Terrasse I dokumentiert wurde und vermutlich zu einem weiteren spätarchaischen Haus gehörte.

Diese Wohnhäuser wurden zu einem noch nicht klar zu fassenden Zeitpunkt, der am wahrscheinlichsten in der ersten Hälfte des 5. Jahrhunderts v. Chr. anzunehmen ist, aufgegeben und sind im heutigen Befund aufgrund der späteren Baumaßnahmen fast nicht mehr zu sehen. Im Bereich des alten, 1978 angelegten Schnitts entstand auf der Oberkante des Lehmziegelversturzes 122/04 bei einem Niveau von rund 80,70 m absoluter Höhe eine Steinsetzung aus Sandsteinen, die zahlreiche Brandspuren sowie im Norden ein über $1 \mathrm{~m}$ langes, verbranntes Brett aufwies (US 124-125/04). Eine Deutung als Feuerstelle liegt nahe, wie sie etwa bei Aufräumungsarbeiten nach der Zerstörung entstanden sein könnte. Auch ein in der Südostecke des Schnitts angetroffenes, sehr fundreiches Stratum aus rötlichem Lehm (123/04) gehört in diese Nachnutzungsphase. Es kann als Teil einer Planierung oder auch als eine nur zu einem sehr kleinen Teil angeschnittene Grube interpretiert werden ${ }^{48}$. Einziger Hinweis auf bauliche Aktivitäten ist ein kurzes, von der Richtung der Polygonalmauer abweichendes Mauerstück, das diese in ihrem Südteil überlagert. Die Mauer ist in der Zeichnung von Johannes Daum (vgl. Beil. 2) auf einer Länge von etwa 1,50 m klar zu erkennen und konnte auch noch 2004 dokumentiert werden, wobei die abweichende Richtung der Steine zunächst mit dem schlechten Erhaltungszustand erklärt wurde ${ }^{49}$. In dieselbe Phase wie diese Mauer könnte auch ein kurzes Mauerstück auf Höhe der Südmauer von Raum 4 gehören, das nach der Zeichnung von Johannes Daum zu ihr, nach der Zeichnung bei Clara Bencivenga hingegen auf die Polygonalmauer im rechten Winkel steht. Da sich von dieser Mauer 2004 keine Spuren mehr fanden, kann hier keine Entscheidung getroffen werden. Klar zu erfassen ist erst wieder die Errichtung der hellenistischen Stadtmauer.

\section{Das Heiligtum des Poseidon Asphaleios im Westteil der Terrasse I}

Der größere Westteil der Terrasse I wird von einer großen Platzanlage eingenommen, die durch eine künstliche Terrassierung des sanft nach Westen abfallenden Hangs entstanden ist. Bei der vollständigen Freilegung des Bereichs durch Pellegrino Sestieri im Jahr 1949 wurde eine dem Poseidon Asphaleios geweihte Stele gefunden, nach der das Heiligtum seine Bezeichnung erhielt ${ }^{50}$. Die Grabungen im Jahr 1971 konzentrierten sich

\footnotetext{
${ }^{47}$ Da zwischen den beiden Gebäuden kein direkter stratigraphischer Zusammenhang hergestellt werden konnte, kann ihre Gleichzeitigkeit nur vermutet werden.

${ }^{48}$ Eine genaue Entscheidung war aufgrund des kleinen Ausschnitts sowie des durch anhaltenden Regen verschärften Wasseraustritts an dieser Stelle nicht möglich.

49 OK der Mauer bei 82,72 absoluter Höhe.

50 Sestieri (Anm. 4) 191-193 Nr. 1861; Guarducci (Anm. 8) 280-282; Napoli (Anm. 10) 33; W. Johannowsky, Considerazioni sullo svilppo urbano e la cultura materiale di Velia, PP 1982, 232-233 Plan; Morel (Anm. 3) 33-49; zuletzt Vecchio (Anm. 3) 50-53 mit ausführlicher Bibliographie.
} 


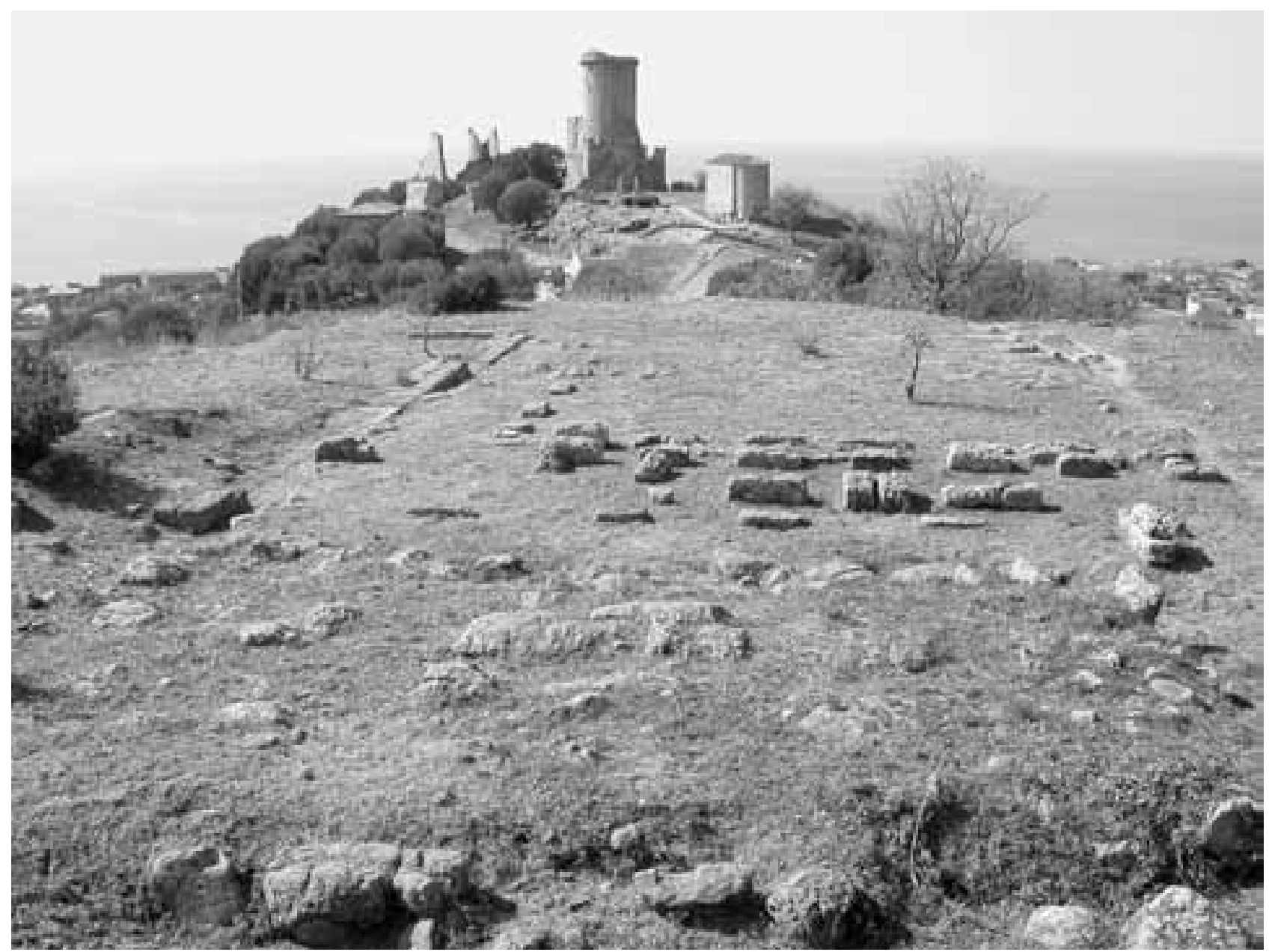

15 Blick von Osten auf das Heiligtum des Poseidon Asphaleios, am linken Bildrand ist der erhöhte Bereich der Südhalle gut zu erkennen

auf den hinter dem eigentlichen Heiligtum nach Osten ansteigenden Hang. Das damals angelegte Quadrantensystem zeichnet sich noch heute deutlich im Gelände ab und kann bei der Beurteilung der Gesamtsituation verwirrend wirken; es ist auch auf dem ersten publizierten Plan des Heiligtums eingezeichnet ${ }^{51}$. Dieser Plan ist allerdings aufgrund eines offensichtlichen Messfehlers leicht verzerrt und konnte nach einer gründlichen Reinigung der Terrasse I in den Jahren 2003 und 2004 durch eine Neuvermessung korrigiert werden, die nun eine bessere Beurteilung der Gesamtsituation erlaubt (Beil. 5) ${ }^{52}$. Zusätzlich konnten mit Hilfe der im Februar 2004 in der Nordostecke der Anlage angelegten Schnitte Erkenntnisse über die Bauabfolge gewonnen werden, aus denen auf eine Zweiphasigkeit des Kultplatzes geschlossen werden kann.

\section{Der Grundriss des Heiligtums}

Zentraler Bereich des mindestens $36 \times 32,60$ m großen Heiligtums ${ }^{53}$ ist ein $24 \mathrm{~m}$ langer und 13,40 m breiter Hof, der im Norden, Osten und Süden von Hallen eingefasst war (Abb. 15; Beil. 5). An der Westseite sind heute mit Ausnahme weniger kleiner Quaderfragmente, die direkt an der Abbruchkante beobachtet wurden,

51 Planabbildungen bei Napoli (Anm. 10) 8; Bencivenga (Anm. 10) Abb. 5.

52 Vermessung durch G. Augustin (Innsbruck). Zusätzlich wurde die Planskizze Beil. 5 im Maßstab 1:100 angefertigt, die allerdings eine wünschenswerte steingerechte Aufnahme nicht ersetzen kann.

${ }^{53}$ Das ergibt 1 173,6 $\mathrm{m}^{2}$. 


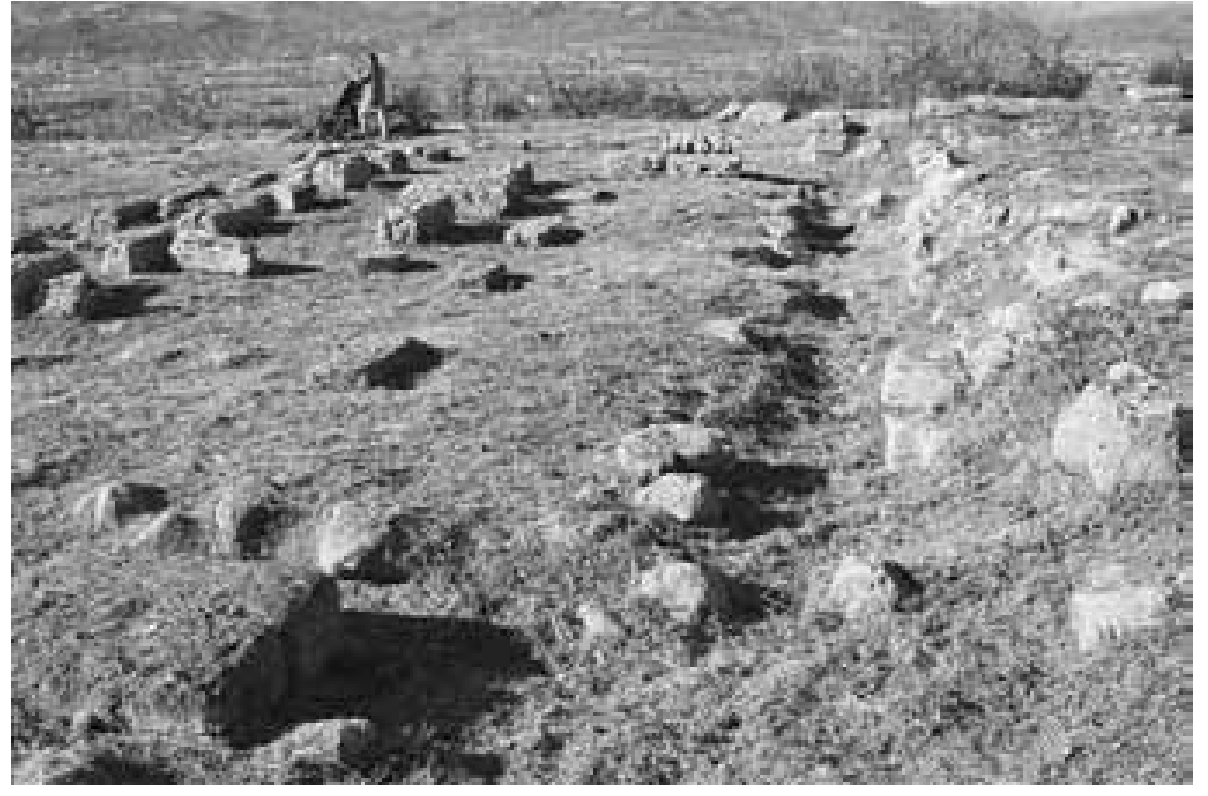

16 Blick von Süden auf die Osthalle des Heiligtums des Poseidon Asphaleios. Im linken Bildteil der sog. Altar und die Basen für Stelen und Anathemata, am rechten Bildrand die Fundamentrinne für die Westmauer der Osthalle keine Spuren von Architektur mehr zu erkennen. Für die Nord- und die Südhalle lässt sich eine Tiefe von 6,30 m rekonstruieren. Ausgangspunkt dafür ist die Südhalle, deren Länge sich an der Nordfront in einer zweischaligen Mauer aus Konglomeratblöcken mit einer Breite von 0,90 m gut erhalten hat. Die Mauer biegt an der Westseite um und lässt sich auf einer Länge von $4 \mathrm{~m}$ verfolgen, die jedoch nicht die ursprüngliche Tiefe der Halle wiedergibt. Diese zeichnet sich in ihrem östlichen Bereich durch den höher anstehenden, d. h. nicht künstlich abgetragenen Fels deutlich im

Gelände ab. An der Südkante ließen sich außerdem eindeutige Abarbeitungen im Fels erkennen, die eine Gesamtbreite von 6,30 m wahrscheinlich machen. Dafür spricht auch die Analyse der Nordhalle. Von ihr hat sich im Ostbereich (Beil. 6) ein Teil der südlichen Mauer (UMA 19) erhalten, der ebenfalls aus Konglomeratquadern besteht. Eine nördliche Abschlusswand der Nordhalle ist im Gelände nicht zu erkennen und müsste - bei einer angenommenen Breite von 6,30 $\mathrm{m}$ - bereits im Nordabbruch liegen. Interessanterweise entsprechen die 6,30 m relativ gut dem Abstand zu der gedachten Verlängerung der Stadtmauer im Abschnitt A0, die damit ursprünglich, wie auch bei anderen Kultplätzen entlang des Mauerzugs A, die Rückwand des Heiligtums und der Nordhalle gebildet haben könnte. An der dem Hof zugewandten Seite dieser Hallen verlaufen Pfeilerportiken. Von ihren Pfeilern haben sich im Süden insgesamt fünf, im Norden nur die geringen Reste zweier Konglomeratblöcke erhalten ${ }^{54}$. Die Breite dieser Portiken beträgt jeweils 3,20 m. Nach Meinung von Pellegrino Sestieri könnten sie mit Velia-Ziegeln gepflastert gewesen sein, wofür auch heute noch sichtbare Ziegelreste im nördlichen Bereich der Oststoa sprechen ${ }^{55}$.

Auch an der Ostseite ist eine Reihe von insgesamt vier Pfeilern aus Konglomeratblöcken deutlich zu erkennen $^{56}$. Nur ganz im Norden liegen statt des zu erwartenden fünften Pfeilers zwei Ost-West orientierte Blöcke, bei denen nicht zu entscheiden ist, ob sie sekundär verlagert wurden oder die Originalsituation, etwa bedingt durch einen hier zu vermutenden Eingangsbereich, wiedergeben. Die nicht mehr im Aufgehenden erhaltene Rückwand der Osthalle lässt sich vielleicht durch deutliche Abarbeitungen im Fels im südlichen Bereich lokalisieren. Der Abstand zwischen ihnen und der Pfeilerreihe würde abermals annähernd 3,20-3,50 m ausmachen, wobei hier zu berücksichtigen ist, dass die Abarbeitungen nicht die eigentliche Mauer, sondern nur die in den Fels eingetieften Fundamentrinnen wiedergeben, sodass mit einem größeren Spielraum zu rechnen ist.

An der Ostseite des Innenhofs liegen unmittelbar vor dieser Ostportikus zwei West-Ost ausgerichtete Konglomeratblöcke, die in einem Abstand von ca. 0,50 m von je einem Nord-Süd orientierten Konglomeratblock flankiert werden, und die beide Spuren von Einlassungen tragen. Südlich davon wurde nach dem Bericht von P. Sestieri ${ }^{57}$ eine weitere Basis mit quadratischer Einlassung gefunden, welche für die erwähnte Stele des

\footnotetext{
${ }^{54}$ Blockmaße 1,00 × 0,40 m, Abstand ca. 1,60 m.

55 Sestieri (Anm. 3) $192 \mathrm{f}$.

${ }^{56}$ Ihr Abstand beträgt ebenfalls jeweils 1,60 m.

57 Sestieri (Anm. 3) 193.
} 
Poseidon Asphaleios bestimmt war. In einem Abstand von rund 1,30 m westlich der mittleren Blöcke fand sich eine doppelte Reihe in Nord-Süd-Richtung orientierter Konglomeratblöcke, zwischen denen sich weitere Sandsteinblöcke sowie vereinzelt Fragmente von Velia-Ziegeln als lockere Füllung befanden. Nur zwischen den mittleren Blöcken der östlichen Reihe ist ein weiterer Konglomeratblock erhalten. Ergänzt man diese Blöcke zu einem zusammengehörigen Objekt, ergeben sie ein 11,60 × 1,70/1,80 m großes, stark gelängtes Monument, das bereits P. Sestieri versuchsweise als Altar bezeichnet hat und das somit das sakrale Zentrum der Anlage darstellen würde.

Analog zur Situation im Norden und Süden wäre auch hinter der Ostportikus eine Halle zu erwarten. Die Interpretation des Bereichs gestaltet sich aber schwierig, da die alten Sondierungsgräben nicht immer eindeutig vom tatsächlichen antiken Befund getrennt werden können. Diese Gräben mit einer wechselnden Breite von 2,5-5 m schließen annähernd U-förmig einen um rund $1 \mathrm{~m}$ erhöhten Mittelteil ein ${ }^{58}$; der Graben im Osten endet nach $11 \mathrm{~m}$ und ist damit kürzer als jener im Westen $(18 \mathrm{~m})$, was vermutlich auf ein vorzeitiges Ende der Grabungstätigkeit zurückzuführen ist. Nach der in der westlichen Sondierung erschlossenen Rückwand der Ostportikus würde man im erhöhten Mittelteil nun die Osthalle erwarten. Der Bereich ist teilweise durch den anstehenden Fels gekennzeichnet und erinnert damit an die Südhalle. In seiner Mittelachse liegen sieben paarweise angeordnete Konglomeratblöcke, von denen das erste und das dritte Paar von Süden wegen ihrer abweichenden Orientierung (Nord-Süd statt Ost-West) auffallen. Bei einer regelmäßigen Ausrichtung sowie dem Einhalten der im nördlichen Teil zu beobachtenden Abstände von jeweils der Breite eines Doppelblocks würden sich insgesamt 8 Paare ergeben ${ }^{59}$. Ergänzen wir diese Blöcke zu einer Pfeilerreihe, so ergeben sich sehr massive Pfeiler mit relativ schmalen Durchgängen mit einer Breite von knapp 0,90 m, was der sonst für zweischiffige Hallen üblichen Jochweite völlig widerspricht ${ }^{60}$. Einarbeitungen im Fels im östlichen Bereich lassen vermuten, dass die Situation hier komplexer war, als heute ohne vollständige Reinigung zu erkennen ist. Von der zu erwartenden Ostmauer der Halle haben sich keine Reste von Quadern erhalten. Sie lässt sich aber wieder durch Abarbeitungen im Fels erkennen, die im östlichen Sondierungsgraben gleich an der Nordostecke zu sehen sind (vgl. Abb. 15, r. im Bildvordergrund) ${ }^{61}$ und auch mit der Westkante von UMA 18, der Abschlussmauer in der Nordostecke, fluchten. Im breiten östlichen Sondierungsgraben sind dies aber nicht die einzigen Abarbeitungen, sondern durch solche sind noch mindestens zwei weitere Fluchten zu erkennen (vgl. Beil. 5), die derzeit nicht gedeutet werden können und vielleicht mit dem älteren Heiligtum in Verbindung stehen. In diesem Zusammenhang ist auch auf einen auffallenden, großen Fels hinzuweisen, der am südlichen Ende des östlichen Sondierungsgrabens aufragt und in gewisser Weise an den Felsen mit der EP-Inschrift in der Unterstadt erinnert ${ }^{62}$. Eine Verbindung mit dem hier ausgeübten Kult in Form eines argos lithos wäre gut vorstellbar, kann derzeit aber in keiner Weise bewiesen werden ${ }^{63}$.

\section{Die Grabungen im Februar 2004}

Diese Beobachtungen zur Gliederung des Heiligtums konnten im Februar 2004 durch Grabungen im Nordostbereich ergänzt werden (Beil. 1. 5-6). Ausgangspunkt dieser Untersuchung war die Klärung der Frage, welche der sichtbaren Mauerreste zur Stadtmauer und welche zum Heiligtum gehörten. Bei Grabungsbeginn deutlich zu erkennen war die von Osten kommende Stadtmauer (UMA 17), die an eine massive Mauer aus Konglomeratblöcken (UMA 18) anstieß, die nach 5,5 m im rechten Winkel umbog (UMA 19). Weiters war in der von diesen Mauern eingeschlossenen Fläche eine in Ost-West-Richtung verlaufende Mauer aus kleineren

\footnotetext{
${ }^{58}$ Durchschnittliches Niveau des Hofs bei 77,00 m absoluter Höhe, das Niveau des anstehenden Fels im Mittelteil beträgt zwischen 78,04 und 78,18 m absoluter Höhe.

59 Gesamtlänge $13,40 \times 0,90 \mathrm{~m}$.

${ }^{60}$ Vgl. H. Lauter, Die Architektur des Hellenismus (1986) 115.

${ }^{61}$ Damit würde sich bei Annahme einer gleich bleibenden Mauerbreite von 0,90 m eine Gesamtbreite der Osthalle von fast $10 \mathrm{~m}$ (Innenraum: 8,20 m) ergeben.

${ }^{62}$ Zu diesem vgl. zuletzt Vecchio (Anm. 3) 62 Nr. 16 Abb. 42 mit der älteren Lit.

${ }^{63} \mathrm{Zu}$ den argoi lithoi vgl. U. Kron, Heilige Steine, in: H. Froning - T. Hölscher - H. Mielsch (Hrsg.), Kotinos. Festschrift E. Simon (1992) 56-70.
} 
Sandsteinblöcken (UMA 20/77 und UMA 16) sowie - in schlechtem Erhaltungszustand - eine diese schneidende Nord-Süd gerichtete Mauer (UMA 21/22) zu erkennen. Die drei Schnitte betreffen einerseits den Innenbereich westlich von UMA 18 (Schnitt 3/04), den Bereich direkt am nördlichen Abbruch (Schnitt 5/04) sowie den Zwickel östlich von UMA 18 mit der Stadtmauer (Schnitt 7/04).

Schnitt 3/04 wurde im Inneren des Heiligtums angelegt und durch die bereits sichtbare Mauer UMA 20/77 in einen Nord- und einen Südteil getrennt (Abb. 17). Im Osten wird der Schnitt durch die 0,95 m breite, aus zwei Reihen von Konglomeratblöcken bestehende Mauer UMA $18^{64}$ begrenzt, von der sich zwei Lagen erhalten haben. In den Blöcken der östlichen oberen Reihe finden sich zwei zylindrische Durchbohrungen, von welchen jene im südlichen Block (706/04 IF) 0,20 m Durchmesser sowie eine Länge von 0,45 m hat. Da hier an der Westseite ein nicht durchlochter Konglomeratblock anschließt, ist die Deutung der Ausnehmung schwierig. Eine etwas kleinere Durchlochung befindet sich wieder im übernächsten Block nach Norden. UMA 18 biegt nach nicht ganz 5,50 m im rechten Winkel nach Westen um, wo sie als UMA 19 - z. T. nur durch Einarbeitungen im anstehenden Fels ${ }^{65}$ - bis auf eine Länge von $4 \mathrm{~m}$ verfolgt werden kann. In ihrer Verlängerung findet sich in einer Distanz von nicht ganz 10 m ein weiterer einzelner Konglomeratblock; kleine Fragmente wurden in einer Entfernung von rund $38 \mathrm{~m}$ am Westende der Terrasse festgestellt. UMA 19 ist damit als Verlängerung der südlichen Begrenzung der Nordhalle aufzufassen. Beim Abtiefen in Schnitt 3/04 zeigte sich, dass UMA 19 und UMA 18 dort, wo sie nicht direkt auf dem anstehenden Fels auflagen, eine Fundamentierung aus unregelmäßigen Sandsteinen (US 318/04 und UMA 76) aufwiesen (Beil. 7) ${ }^{66}$. Vom ursprünglichen Nutzungsniveau fanden sich unmittelbar westlich von UMA 19 drei nur im Ansatz erhaltene VeliaZiegel (310/04) ${ }^{67}$ als Rest einer ursprünglichen Ziegelpflasterung des Raumes.

Anders ist die Situation im Nordostteil des Schnitts nördlich von UMA 20 (Beil. 7): Hier liegt unter den Konglomeratblöcken von UMA 18 eine Lage flacher Sandsteinblöcke auf dem gewachsenen, aber an der Oberseite entsprechend abgearbeiteten Fels (312/04) auf, bei der es sich eindeutig nicht um ein Fundament, sondern um eine ältere Mauer handelt (UMA 74), wie aus dem im Osten anschließenden Schnitt 7/04 hervorging $^{68}$. Sie biegt etwa in der Mitte von UMA 18 im rechten Winkel nach Westen und setzt sich als UMA 20 fort. UMA 20 ist eine ca. 0,50 m breite Mauer aus zwei Reihen kleinerer, unregelmäßig fundamentierter Sandsteinquader, deren Zwischenraum stellenweise mit sehr kleinen Steinen verfüllt ist. Über diesen Quadern lagen horizontal verlegte Platten, von denen sich 1,80 m von UMA 74/78 entfernt noch drei gefunden haben.

Diese Mauer wurde in den gelben Sand hineingesetzt ${ }^{69}$, der über und zwischen dem in großen Knollen anstehenden natürlichen Sandstein liegt ${ }^{70}$. Seine Oberfläche fällt, wie das Gelände auch heute noch, von Osten nach Westen sowie von Süden nach Norden $\mathrm{ab}^{71}$. Im Westprofil lässt sich zu UMA 20 eine Baugrube (US 320/04 IF) mit der Verfüllung 321/04 sowie ein durch die Steinplatten 313/04 angegebenes Benutzungsniveau erkennen $^{72}$. UMA 20 endet an der Schnittgrenze des Ostteils. In ihrer unmittelbaren Verlängerung liegen Sandsteinblöcke (UMA 77), die sich durch Farbe und Form ebenso deutlich von UMA 20 unterscheiden wie durch ihre stratigraphische Relation. Da UMA 77 eindeutig nicht auf dem gelben Sand, sondern über dem sandigen Stratum 301/04 liegt, muss sie jünger oder bei den älteren Grabungen bewegt worden sein. Mit ihr

\footnotetext{
${ }^{64}$ Größter Block 1,30 × 0,45 × 0,45 m.

${ }^{65}$ Fels: 308/04 und 324/04; Einarbeitungen: US 309/04 IF, 317/04 IF, 325/04 IF.

${ }^{66}$ UMA 76 wurde zunächst als eigene Einheit behandelt, da die Steine flacher und grau verfärbt sind, was aber auf ein längeres Offenstehen des Bereichs zurückzuführen ist. Die stratigraphische Position von UMA 76 entspricht jener von US 318/04.

${ }^{67}$ Größe der Ziegel 0,34 × 0,18 × 0,09 m, UK liegt bei etwa 77,70 m absoluter Höhe.

${ }^{68}$ In Schnitt 7/04 wurden die Mauerblöcke zunächst als UMA 78 bezeichnet. Die gesamte Mauerbreite beträgt fast $1 \mathrm{~m}$. Zum Schnitt 7/04 s. u.

69 303/04 im Nordostteil, 304/04 im Südostteil.

70 305/04 und 323/04 im Nordostteil, 306/04 und 322/04 im Südostteil. Die zweite US-Nummer bezeichnet jeweils den im unteren Bereich etwas feineren Sand.

${ }^{71}$ OK im Norden bei 77,60 (Ostbereich), 77,45 (Westbereich), OK im Süden bei 77,70 (Ostbereich), 77,50 m (Westbereich) absoluter Höhe.

${ }^{72}$ Dieses korrespondiert mit der Oberkante von 304/04, wobei sich durch die neuzeitliche Grabungstätigkeit nicht mehr feststellen lässt, ob die Oberkante von 304/04 die ursprüngliche ist.
} 


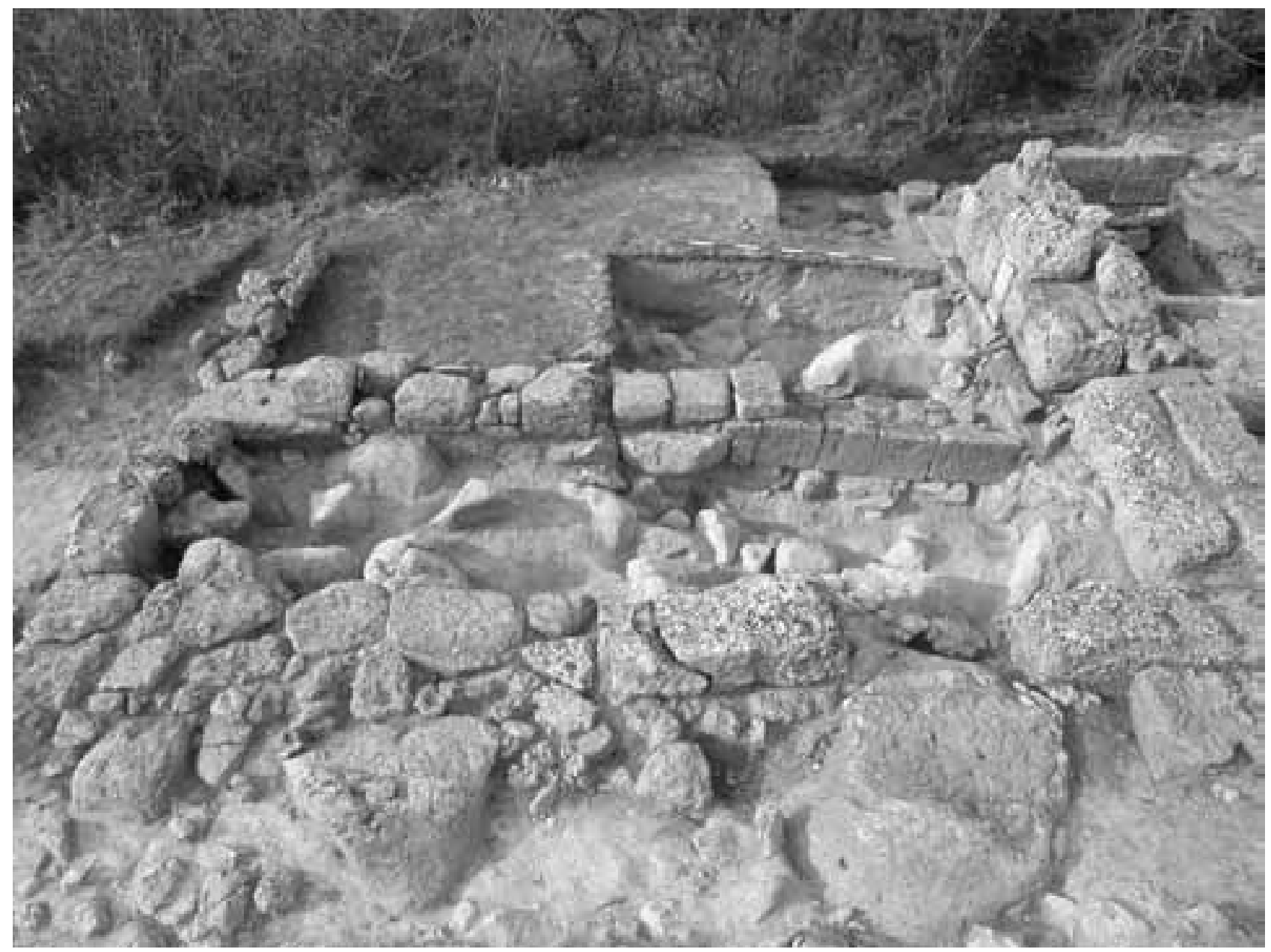

17 Terrasse I West, Schnitt 3/04: Blick von Süden

gleichzeitig könnten die zu einer Nord-Süd-Mauer gehörenden Mauerteile UMA 21 und 22 sein, die in der Steintechnik ähnlich, mit ihr jedoch nicht in erkennbarer Weise verbunden sind. Außerhalb des Schnitts 3/04 wurde in einem Abstand von 1,80 m vom Westende von UMA 77 eine weitere Ost-West verlaufende Mauer freigeputzt (UMA 16), deren sichtbare oberste Lage aus flachen Sandsteinplatten besteht, die an jene von UMA 20 erinnern. Daher wird UMA 16 zunächst der älteren Phase zugewiesen. UMA 74/78 und UMA 20/16 ergeben somit die Ecke eines langgestreckten Raums, der auf eine Länge von 10,90 m und eine Breite von 4,40 m erhalten ist und vorläufig als Halle angesprochen werden kann.

In der Nordwestecke von Schnitt 3/04 wurde eine größere Grube (US 316/04 IF) angeschnitten, die mit einer dunklen, lehmigen und mit Holzkohlestückchen versetzten Masse verfüllt (US 316/04, vgl. Beil. 7) ${ }^{73}$, sonst aber fundleer war. Südlich von ihr fand sich eine Art Pfostenloch (US 314/04 IF) mit einer sandigen Verfüllung (US 315/04). Beide Phänomene sind von der Oberkante des Sandes US 304/04 aus abgetieft, ohne dass sich entscheiden lässt, ob diese der ursprünglichen Situation entspricht. Die Grube US 316/04 setzt sich auch im nach Nordosten anschließenden Schnitt 5/04 fort. Auch in diesem Schnitt lässt sich zunächst der gelbe Sand (US 502/04, 508/04) beobachten, der im Ostteil sehr massiv ansteht, gegen Westen hin jedoch ausdünnt; er liegt hier auf einem rötlichen Lehm (US 510/04) auf. In diese beiden Straten schneidet - vermutlich von der Oberkante von US 502/04 - eine Grube (US 511/04 IF) ein, die mit US 316/04 IF in Schnitt 3/04 identisch ist. Ihre östliche Kante verläuft nahe der Schnittgrenze und ist nach Norden zu durch den Abbruch gestört. Ihre

\footnotetext{
${ }^{73}$ Maße: 1,60 m von der Nordwestecke nach Süden, 1,70 m nach Osten.
} 


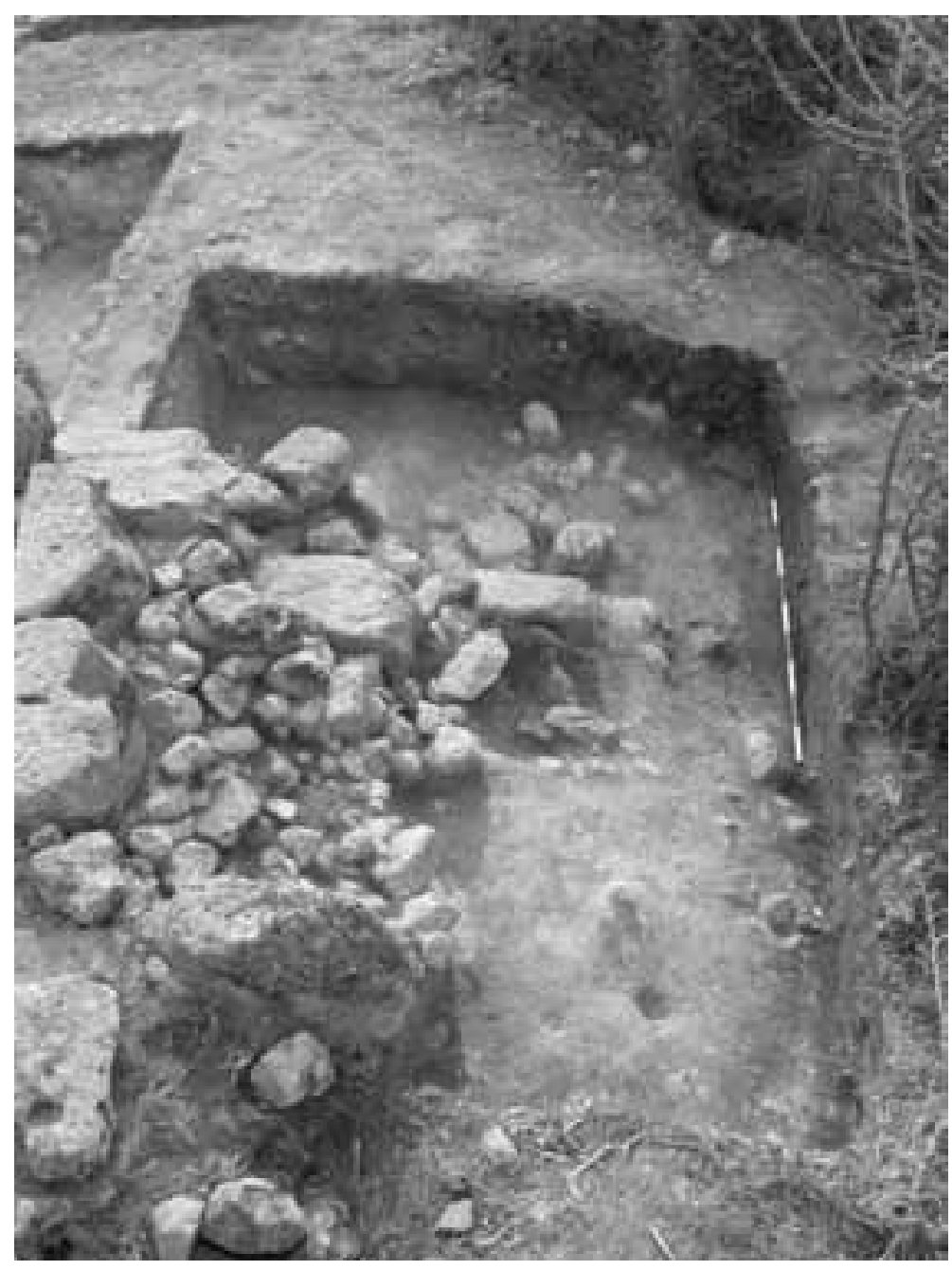

18 Terrasse I West, Schnitt 5/04: Blick von Osten auf die nach Norden verstürzte Kurtine UMA 17 genaue Abgrenzung zu US 510/04 war nur schwer nachzuvollziehen ${ }^{74}$. Ihre Verfüllungen (US 509/04) und die darüber liegende Schicht US 503/04 bestanden jeweils aus Lehm, der im unteren Teil von starken Brandspuren (Holzkohle, rot verbrannte Sandsteine) gekennzeichnet war; im oberen Teil im Bereich des Stratums US 503/04 war der Lehm graubraun und sehr fundreich. Damit steht die Verfüllung im Gegensatz zu jener von US 316/04. Möglicherweise ist dies auf den Ablauf des Verfüllungsprozesses der Grube zurückzuführen. Die durchweg qualitätsvollen Funde sind noch nicht bearbeitet, gehören jedoch nach derzeitigem Wissensstand alle der spätarchaischen Zeit $\mathrm{an}^{75}$. Ein Zusammenhang mit einem frühen Kultplatz ist nicht vollkommen von der Hand zu weisen. Zwei weitere Verfärbungen (US 504/505 und 506/507) wurden im Bereich westlich von UMA 74/78 im Stratum US 510/04 beobachtet; ihre Bedeutung war nicht festzustellen.

Am aufschlussreichsten für die Chronologie des Heiligtums war Schnitt 7/04, der im Zwickel östlich von UMA 18 und südlich der Stadtmauer UMA 17 angelegt wurde $^{76}$. Die von Osten kommende Stadtmauer ist hier mit einer Breite zwischen 1,30-1,65 m erhalten, ihr nördlicher Teil ist durch den Steilabbruch völlig zerstört. Die südliche Mauerschale (UMA 17) be-

steht aus 0,80 × 0,40 × 0,50 m großen Sandsteinblöcken (Beil. 8 und Abb. 19), die auf einem dreilagigen Fundament (US 703/04) aufliegen, das in den beiden oberen Reihen aus unregelmäßig bearbeiteten Sandsteinblöcken ${ }^{77}$, in der untersten Schar aus kleineren Sandsteinen besteht. Diese Fundamentierung wurde mit einer Mächtigkeit von insgesamt 0,70 m bis zum gewachsenen Fels abgetieft. Das bei einer absoluten Höhe von 78,20-78,25 m (= Unterkante von UMA 17) anzunehmende Bauniveau der Stadtmauer ist stratigraphisch nicht mehr erhalten, da das oberste humose Stratum 701/04 bis in eine Tiefe von etwa 77,95 m absoluter Höhe reicht. Stratum 701/04 ist rezenter Entstehung, enthielt jedoch ein fast vollständig erhaltenes, weibliches Terrakottaköpfchen mit Polos.

Die Kurtine setzt an eine ältere Nord-Süd verlaufende Mauer aus großen Sandsteinblöcken an, deren Westseite wir als UMA 74 bereits beschrieben haben. Sie ist insgesamt nicht ganz $1 \mathrm{~m}$ breit und besteht aus zwei Reihen unterschiedlich gestalteter Sandsteinblöcke. Die westliche Schale (UMA 74) ist durch flache Sandsteinblöcke charakterisiert, deren Unterkante bei 77,60 m absoluter Höhe liegt (vgl. den Mauerschnitt Beil. 8). Die östliche Schale (UMA 78) besteht hingegen aus großen Sandsteinquadern, die direkt auf dem

\footnotetext{
${ }^{74}$ Anhaltende Regenfälle führten zu einer völligen Aufweichung des Bereichs. Bei einer wahrscheinlichen Erstreckung im Westprofil von rund 2 m nach Norden ergibt dies für die Grube insgesamt einen Mindestdurchmesser von über 3,5 m.

${ }^{75} \mathrm{Zu}$ erwähnen sind Knickrandschalen sowie mehrere westgriechische Amphoren dieser Zeit.

${ }^{76}$ Maße 1,60 (Ost-West) × 1,80 m (Nord-Süd).

77 Durchschnittliche Größe 0,25 × 0,35 × 0,70 m.
} 
gewachsenen Fels aufliegen ${ }^{78}$. Dieser ist an der Nordseite blockartig abgearbeitet (US 705/04), während die nach Süden anschließende, stärker vorspringende Felsknolle 710/04 nur eine glatt abgearbeitete Oberfläche (711/04 IF) besitzt.

\section{Chronologische Einordnung und Kultinhaber des Heiligtums}

Die beschriebenen Grabungen im Nordostteil des Heiligtums, vor allem Schnitt 7/04, geben eine klare relative Abfolge der Bauaktivitäten: Erste für uns fassbare architektonische Gestaltung des Platzes ist die Errichtung einer Ost-West orientierten Halle, von der wir die Mauern UMA 20 und UMA 74/78 kennen. An diese Halle wird zu einem späteren Zeitpunkt auf deutlich höherem Niveau die Kurtine angesetzt, die hier - vielleicht um das Heiligtum zu respektieren - nach Norden umbiegt. In einer dritten Bauphase erfolgte schließlich die vollständige Neugestaltung des Heiligtums in der heute bekannten Form. Der Versuch einer absolutchronologischen Einordnung dieser drei Bauphasen sieht sich mit der Schwierigkeit konfrontiert, dass der größte Teil des Heiligtums bereits 1926 und 1949 bis zum anstehenden Fels freigelegt wurde ${ }^{79}$; eine detaillierte Stratenabfolge war demnach für die Grabungen 2004 nicht mehr zu erwarten. Ausgangspunkt für unsere Überlegungen ist daher die Kurtine UMA 17, die nach ihren Konstruktionsmerkmalen der Periode 3 der Befestigung zuzuschreiben ist. Für diese haben die jüngsten Arbeiten gezeigt, dass sie vermutlich in das erste Viertel des 3. Jahrhunderts v. Chr. zu datieren ist. Allerdings gibt es Hinweise auf eine zweite hellenistische Bauphase, die etwas später datiert und bis jetzt vor allem in der Unterstadt fassbar war ${ }^{80}$. Die Mauer UMA 74/78 des älteren Heiligtums muss daher einige Zeit vor dem ersten Viertel des 3. Jahrhunderts v. Chr. errichtet worden sein. Dies könnte mit dem zeitlichen Ansatz korrespondieren, den wir durch die Datierung der Stele des Poseidon Asphaleios erhalten: Diese war von Margherita Guarducci aufgrund des Schriftcharakters in die erste Hälfte des 4 . Jahrhunderts v. Chr. gesetzt worden ${ }^{81}$. Wir können daher davon ausgehen, dass auf der Terrasse I seit der ersten Hälfte des 4. Jahrhunderts v. Chr. ein Heiligtum für Poseidon existierte, dessen bauliche Überreste möglicherweise in der beschriebenen Halle gesehen werden können ${ }^{82}$. Das Heiligtum erfuhr in einer weiteren Bauphase, die aufgrund der Bau- und Benutzungsniveaus eindeutig nach der Errichtung der Kurtine anzusetzen ist, seine monumentale Ausgestaltung in der heute sichtbaren Form. Damals muss auch die Stele des Poseidon Asphaleios an den Platz an der Ostseite des Hofs gekommen sein, an dem Pellegrino Sestieri sie später gefunden hat. Für diesen Neubau könnten sowohl die zweite Hälfte des 3. Jahrhunderts v. Chr. als auch das 2. Jahrhundert v. Chr. in Frage kommen.

Das Jahr 2004 brachte noch eine weitere Entdeckung zu dem Heiligtum auf der Terrasse I, die nicht im Gelände, sondern im Velia-Archiv des Instituts für Klassische Archäologie der Universität Wien stattfand. Bei Ordnungsarbeiten wurde eine Schachtel mit alten Schwarz-Weiß-Abzügen im typischen Kleinformat der vierziger und fünfziger Jahre des 20. Jahrhunderts gefunden, von denen einige auf der Rückseite mit Bleistift beschriftet waren. Bald war klar, dass es sich dabei um einen Teil der Originalphotodokumentation Pellegrino Sestieris handelte, der unter nicht mehr nachvollziehbaren Umständen in das Velia-Archiv gelangt ist ${ }^{83}$. Neben Photographien der Stele des Poseidon Asphaleios und einigen derzeit nicht zu identifizierenden Detailaufnahmen der Grabung fanden sich zwei Abbildungen, die von besonderer Bedeutung sind: Eine (Abb. 20) zeigt eine Gesamtansicht des Heiligtums von Südwesten, auf der im Vordergrund die Südhalle sowie die Pfeilerreihe der ihr vorgelagerten Portikus zu erkennen sind. Im Hintergrund blicken wir auf den zum größten

${ }^{78}$ Größe der Quader 0,75 × 0,70 × 0,55 m. Das Bauniveau liegt bei 77,67 m absoluter Höhe und springt im südlichsten in Schnitt 7/04 ergrabenen Block auf 77,53 m absoluter Höhe.

${ }^{79}$ Aus den älteren Grabungen sind bis jetzt keine Funde bekannt, doch ist zu hoffen, dass solche bei einer Sichtung der Altfunde im Depot noch gefunden werden.

${ }^{80}$ Vgl. die Analyse von M. Trapichler in: Gassner - Sokolicek - Trapichler (Anm. 12:2003) 84 ff.

${ }^{81}$ Guarducci (Anm. 8) 280-282; Vecchio (Anm. 3) 50 Nr. 7.

${ }^{82}$ Auf die Existenz eines noch früheren Heiligtums könnten die Funde aus der Grube 316/04 IF hinweisen, die aber keinen eindeutig sakralen Charakter aufweisen.

${ }^{83}$ Weitere Nachforschungen erbrachten auch noch die - teilweise stark beschädigten - Negative zum Vorschein. Mein Dank gilt Luigi Vecchio (Salerno), der aus seiner Beschäftigung mit der Forschungsgeschichte Velias die Handschrift als jene P. Sestieris identifizieren konnte. 


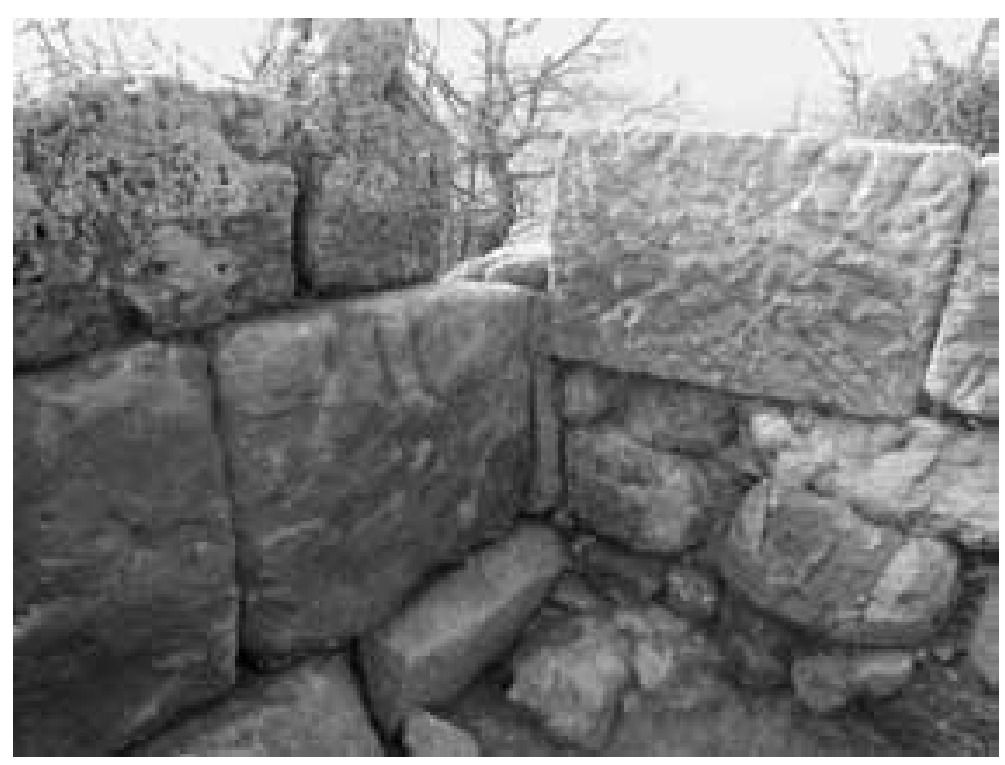

19 Terrasse I West, Schnitt 7/04: Blick auf die Nordwestecke. Links die großen Sandsteinquader UMA 78 des älteren Heiligtums, auf ihnen ein Konglomeratquader von UMA 18, rechts im Bild die Stadtmauer UMA 17 mit tiefer Fundamentierung

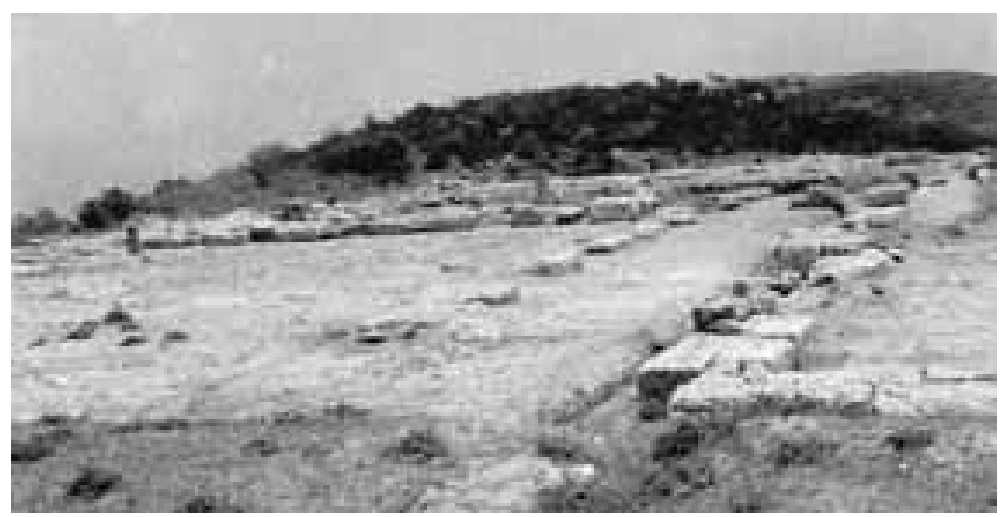

20 Das Heiligtum des Poseidon Asphaleios von Westen. Aufnahme aus dem Jahr 1949 (?), vermutlich von P. C. Sestieri
Teil geputzten, höher gelegenen Ostbereich, vor dem der sog. Altar und die wiederaufgerichtete Stele des Poseidon Asphaleios zu sehen sind ${ }^{84}$. Unerwartet ist die Existenz einer weiteren, ebenfalls wiederaufgestellten Stele, die am linken Bildrand im nordöstlichen Bereich des Hofs westlich des Altars deutlich zu erkennen ist. Noch interessanter ist das zweite Photo (Abb. 21), das eine Stele mit Inschrift zeigt, bei der es sich ganz offensichtlich um jene Stele der Hera handelt, deren Fundort bisher als unbekannt angenommen wurde ${ }^{85}$. Die handschriftliche Beschriftung auf der Rückseite mit »terrazza B cippo « weist diese nun eindeutig dem Heiligtum auf der Terrasse I zu, wenn wir nicht von dem unwahrscheinlichen Fall ausgehen wollen, dass Pellegrino Sestieri sich gerade bei der Beschriftung dieses wichtigen Bildes geirrt hätte. Im Heiligtum auf der Terrasse I waren also zumindest zwei Stelen aufgestellt, deren Fundort wir vermutlich durch die Gesamtaufnahme Abbildung 20 erschließen können. Die Frage, ob die Stele der Hera mit der auf diesem Photo erkennbaren zweiten Stele identisch ist, lässt sich aufgrund der geringen Größe der Aufnahme nicht eindeutig, aber doch mit einiger Wahrscheinlichkeit positiv beantworten ${ }^{86}$.

Damit eröffnet sich ein weites Feld für die Neuinterpretation des Kultplatzes 2, der offensichtlich zwei Gottheiten, näm-

lich Poseidon und Hera, geweiht war. Eine Doppelweihung war schon von Pellegrino Sestieri aufgrund der zwei symmetrisch angeordneten Stelenbasen östlich des sog. Altars vermutet worden. Als weibliches Pendant zu Poseidon nahm er - wie auch einige Forscher nach ihm - Aphrodite Euploia an, während Jean-Paul Morel auch an Leukothea denken wollte ${ }^{87}$. Durch die neue Zuordnung der Hera-Stele zeigt sich, dass auf Terrasse I tatsächlich eine zweite, weibliche Gottheit verehrt wurde, die Kultgemeinschaft Poseidons mit Hera wirkt auf den ersten Blick freilich etwas überraschend ${ }^{88}$.

\footnotetext{
${ }^{84}$ Interessant ist auch die Tatsache, dass der nach Osten folgende Hang 1949 noch vollständig von Macchia überwachsen war, die vermutlich erst unter M. Napoli abgeholzt wurde.

85 Vecchio (Anm. 3) 55 Nr. 10.

86 Theoretisch möglich wäre, dass es sich um eine der beiden bereits 1926 von A. Maiuri gefundenen Stelen handelt, vgl. dazu ausführlich Vecchio (Anm. 3) 50 f., doch fragt sich, wieso dann nur eine wieder gefunden worden wäre.

${ }^{87}$ P. C. Sestieri, Greek Elea - Roman Velia, Archaeology 10, 1957, 5. Zur weiteren Aufnahme dieser These vgl. Morel (Anm. 3) $40 \mathrm{f}$.

${ }^{88}$ Vgl. zu den seltenen Kultgemeinschaften des Poseidon E. Wüst in: RE XXII 1 (1953) 509 f. s. v. Poseidon; zur Situation auf der Peloponnes vgl. J. Mylonopoulos, Heiligtümer und Kulte des Poseidon auf der Peloponnes, 13. Suppl. Kernos (2003) $401 \mathrm{ff}$. Interessanterweise kommt hier eine Kultgemeinschaft mit Hera überhaupt nicht vor.
} 
Die Verehrung von Hera ist in Velia mit insgesamt vier Inschriften belegt ${ }^{89}$. Zwei stammen von Horoi aus Sandstein (Vecchios Nr. 9 und 10), während Vecchios Nr. 11 am wahrscheinlichsten als Bauinschrift auf einem Architrav interpretiert werden kann. Nr. 12 bei Luigi Vecchio ist eine von Olga Salvadego Molin Ugoni gesehene Inschrift auf einem Block der Stadtmauer (MZA) in der Nähe von Turm A 6, die heute nicht mehr aufzufinden ist, und von der sich keine graphische oder photographische Dokumentation erhalten hat. Die ersten drei Inschriften können anhand der epigraphischer Kriterien in das 4. Jahrhundert v. Chr. datiert werden. Als Zeugnis des Herakults sind Graffiti auf Trinkschalen des 5. Jahrhunderts v. Chr. aus dem Votivdepot auf der Akropolis anzuführen, die allerdings nicht eindeutig dieser Göttin zugeordnet werden können ${ }^{90}$. Von besonderem Interesse ist in diesem Zusammenhang Vecchios Inschrift Nr. 9 ${ }^{91}$, denn in ihr führt Hera den Beinamen Thelxine. Die Inschrift findet sich auf einer Stele unbekannte Fundorts, die in Form und Art jener für Poseidon Asphaleios entspricht, mit der sie aus epigraphischen Gründen auch in der Datierung übereinstimmt. Die Interpretation der singulären Epiklese Thelxine beschäftigt die Forschung seit längerem: Margherita Guarducci führte sie auf athenischen Einfluss zurück und schlug aufgrund der etymologischen Ableitung eine Deutung als »Hera, die bezaubert, die besänftigt « vor, worin ihr die weitere Forschung mehrheitlich folgte ${ }^{92}$. In jüngster Zeit hat Luigi Vecchio darauf hingewiesen, dass das der Epik-

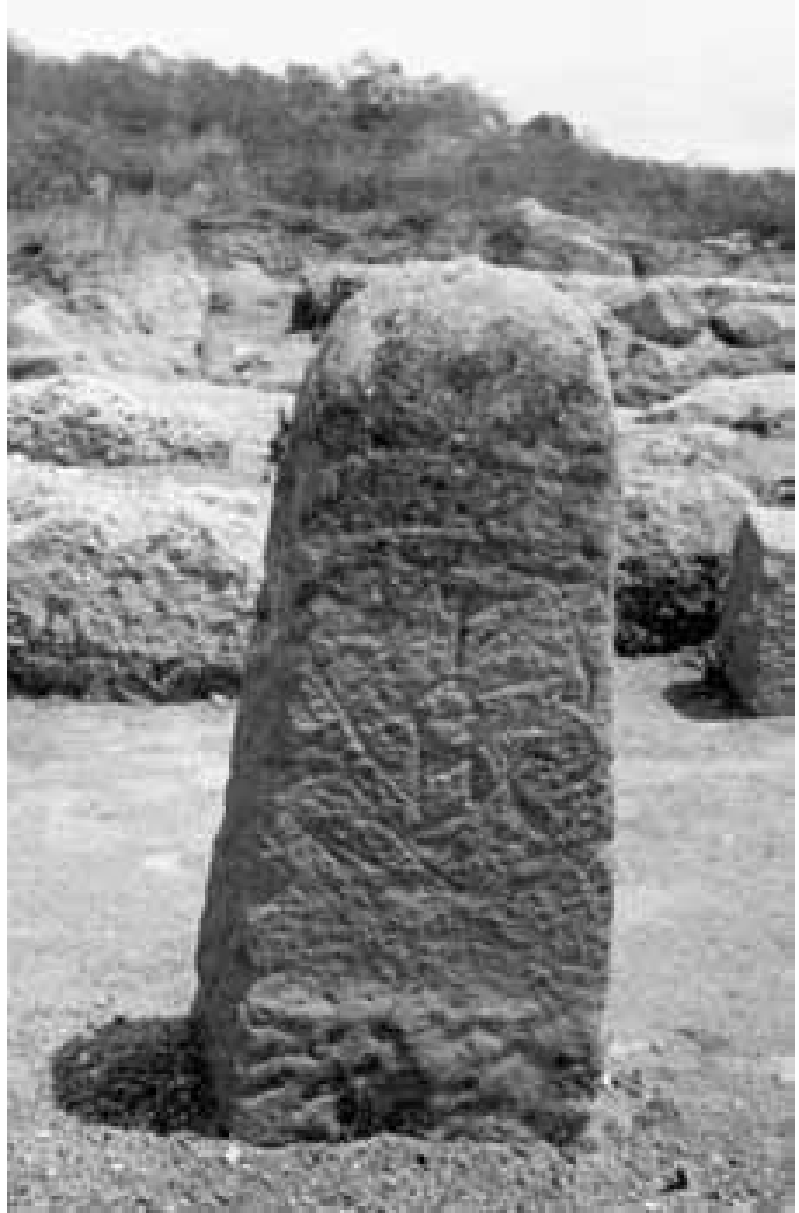

21 Stele mit Inschrift für Hera (Vecchio [Anm. 3] Nr. 10 Taf. 11, 38). Aufnahme aus dem Jahr 1949 (?), vermutlich von P. C. Sestieri lese zugrunde liegende Verbum $\theta \varepsilon ́ \lambda \gamma \varepsilon ı$ bei Homer in Verbindung mit den Sirenen gebraucht wird und auch im Namen einer der Sirenen, Thelxiope, enthalten ist ${ }^{93}$. Nach dieser Interpretation hätte Hera Thelxine in Velia als die Besänftigerin der Winde eine für die Schifffahrt wichtige Funktion eingenommen und wäre als solche auch als Kultpartnerin des Poseidon gut vorstellbar. Die dem Kultplatz des Poseidon Asphaleios zuordenbare Stele trägt nun freilich nur den Namen der Hera ohne weitere Zusätze, sodass allzu weit reichende Schlüsse kaum zulässig sind. Dennoch scheint mir dieser besondere Aspekt der Hera in Velia für das Verständnis ihres gemeinsamen Auftretens mit Poseidon nicht unwichtig zu sein, denn so nähert sich das Bild der auf der Terrasse I verehrten Hera dem Vorschlag Jean-Paul Morels an, der für die Kultgemeinschaft mit Poseidon Asphaleios Leukothea vorgeschlagen hat, die ihrerseits wieder Ähnlichkeiten mit der am nahe gelegenen Kap von Licosia verehrten Sirene Leukosia hat ${ }^{94}$.

Betrachten wir das Heiligtum in seiner architektonischen Form, so zeigt es ebenfalls außergewöhnliche Merkmale, die eine Einordnung nicht einfach machen und eine lohnende Aufgabe für künftige Forschungen

\footnotetext{
${ }^{89}$ Vecchio (Anm. 3) 54-58 Nr. 9-12.

${ }^{90}$ Vgl. zusammenfassend G. Tocco Sciarelli, Il culto di Hera ad Elea, in: J. de la Genière (Hrsg.), Héra. Images, espaces, cultes. Actes du Colloque International du Centre de Recherche Archéologiques de l’Université de Lille III et de l'Association P.R.A.C. Lille, 29-30 novembre 1993 (1997) 231-234; dies., Aspetti del culto in età arcaica ad Elea, in: F. Krinzinger (Hrsg.), Die Ägäis und das westliche Mittelmeer. Akten des Symposions Wien 1999, AForsch 4 (2000) 54 sowie zusammenfassend Vecchio (Anm. 3) $54 \mathrm{f}$.

91 Vecchio (Anm. 3) 54 Nr. 9.

${ }_{92}$ M. Guarducci, Nuovi Cippi sacri a Velia, PP 1970, 256-259; Morel (Anm. 3 ) 38 mit der neueren Lit.

${ }^{93}$ Vecchio (Anm. 3) $55 \mathrm{f}$.

${ }^{94}$ Morel (Anm. 3) 37 und 40.
} 
darstellen. Fassen wir seine Charakteristika nochmals zusammen: Es handelt sich um eine große Platzanlage, die an drei Seiten von Pfeilerportiken umgeben war, hinter denen sich Hallen befanden, deren Niveau im Norden und Osten nach Aussage des anstehenden Fels deutlich höher war als jenes des Hofs. Obwohl sich keine Reste von Architekturteilen erhalten haben, lässt sich daraus auf einen monumentalen Charakter der Anlage schließen. Die Halle im Osten war mit über $8 \mathrm{~m}$ breiter als jene im Süden und Norden. In ihrer Mittelachse lag eine Doppelreihe von Konglomeratblöcken, deren Deutung unklar ist. An der östlichen Schmalseite des Hofs befand sich ein bis knapp an die Portiken reichender, langgestreckter Altar ${ }^{95}$, unmittelbar hinter diesem Basen für Stelen und Weihgeschenke (?). Vor dem Altar lag, etwas aus der Mittelachse nach Süden gerückt, eine etwa 0,5 m tiefe, kreisrunde Vertiefung, deren Funktion nicht ganz klar ist. Der Hofboden bestand, soweit dies heute zu erkennen ist, aus dem anstehenden, künstlich geebneten Fels. Reste von Bothroi oder anderen Kulteinrichtungen konnten an keiner Stelle beobachtet werden.

Von Säulen- oder Pfeilerhallen umgebene Höfe sind ein charakteristisches Element der hellenistischen Architektur, in welcher sie uns in verschiedenen Kontexten begegnen. Ab dem Frühhellenismus werden auch zahlreiche Heiligtümer mit Säulenhallen ausgestattet, die neuen Gestaltungsprinzipien folgen und ab nun die Raumgestaltung bestimmen ${ }^{96}$. Dies lässt sich besonders eindrucksvoll an großen Terrassenanlagen wie etwa dem Asklepieion von Kos oder dem Athenaheiligtum von Lindos verfolgen, wird aber auch in der Umgestaltung kleinerer Temene, wie z. B. des heiligen Bezirks in Dodona, sichtbar. Bei all diesen Heiligtümern wird der Hof mit dem Altar aber in der Regel von einem Tempelbau ergänzt, der - im Hof platziert, in die Säulenarchitektur integriert oder auf einer darüber liegenden Terrasse prominent hervorgehoben - ein wichtiges Element der Architektur und wohl auch des Kultbetriebs bildete. Das Fehlen eines solchen Tempelgebäudes unterscheidet nun das Heiligtum des Poseidon Asphaleios von anderen, gleichsam 'kanonischen' hellenistischen Anlagen. Eine mögliche Ergänzung im Osten, wo der ansteigende Hang seine erhöhte Position begünstigt hätte, scheint nach der heute dort vorgefundenen Situation nicht wahrscheinlich ${ }^{97}$. Ebenso wenig gibt es Spuren eines Tempels an der offenen Westseite.

Wir haben also nach derzeitigem Forschungsstand eine Hofanlage ohne Naos vor uns, für welche wir vermuten können, dass der Altar im Zentrum der Kulthandlungen stand. Derartige Anlagen sind gerade aus Großgriechenland bekannt: Temene mit einem Altar, aber ohne Tempel, gibt es etwa im Zentrum von Metapont, doch sind ihre Dimensionen deutlich kleiner als jene des velinischen Heiligtums ${ }^{98}$. Bekanntes Beispiel eines Kultzentrums ohne eigentlichen Tempel ist auch das ebenfalls direkt an den Stadtmauern gelegene Heiligtum der Aphrodite in Centocamere in Lokroi, dessen großer Hof an drei Seiten von Portiken umgeben ist, hinter denen gleich große Kammern lagen ${ }^{99}$. Hier enden freilich schon die Gemeinsamkeiten, denn in Lokroi fehlt der große, langgestreckte Altar; dafür fanden sich im Hof unzählige Bothroi als Zeugnisse der Kulthandlungen, die wiederum in Velia nicht belegt sind. Auch zeitlich ist zwischen dem in zwei Schritten im 6. Jahrhundert v. Chr. entstandenen Heiligtum der Aphrodite und der hellenistischen Anlage auf Terrasse I ein deutlicher Unterschied.

Dem Heiligtum des Poseidon Asphaleios zeitlich näher stehend sind andere Kultplätze, auf deren Bedeutung für Velia erst in jüngster Zeit hingewiesen wurde ${ }^{100}$, nämlich die sog. lukanischen Heiligtümer, die uns seit der Mitte des 4. Jahrhunderts v. Chr. an verschiedenen Orten begegnen. Ihre Erforschung hat in den letzten Jahren bedeutende Fortschritte gemacht, sodass wir nun Varianten erkennen können ${ }^{101}$. Zu den bereits

\footnotetext{
${ }^{95}$ Der Abstand des Altars zu den Portiken beträgt rund 0,90 m, also 3 Fuß, wobei genaue Kalkulationen aufgrund der Tatsache, dass ihnen nur eine Maßskizze zugrunde liegt, hinfällig sind.

${ }^{96}$ Vgl. dazu und zu den folgenden Beispielen Lauter (Anm. 60) 99 ff.; G. Gruben, Die Tempel der Griechen ${ }^{5}$ (2001) 404 ff.

${ }_{97}$ Auch die zuvor im Abschnitt »Der Verlauf der Stadtmauer« beschriebenen vereinzelten Steinblöcke in Schnitt 6/04 liegen nicht axial auf die Platzanlage ausgerichtet und lassen vor allem keine Nord-Süd-Mauern erkennen. Der Bereich des spätarchaischen Antenhauses A.I. wiederum ist in hellenistischer Zeit so in die Stadtmauer inkorporiert, dass ein Kultgebäude in Form eines Tempels schwer vorstellbar erscheint.

98 A. De Siena, Metaponto. Problemi urbanistici e scoperte recenti, in: Siritide e Metapontino. Storie di due territori coloniali, Cahiers du Centre Jean Bérard 20 (1998) 141-170 bes. 151 ff.

${ }^{99}$ Vgl. G. Gullini, La cultura architettonica di Locri Epizefirii (1980) $111 \mathrm{ff.}$

${ }^{100}$ G. Greco, Paestum ed Elea tra Magna Grecia e Roma, in: CMGR 44 (2004) 577-641 bes. 616 ff. Ich danke Giovanna Greco für die freundliche Erlaubnis, ihr ungedrucktes Manuskript einzusehen und für interessante Diskussionen zu diesem Thema.

101 Zusammenfassend vgl. zuletzt M. Barra Bagnasco - A. Russo Tagliente, I culti, in: Greci, Enotri e Lucani nella Basilicata Meridionale (1996)183-193.
} 
lange bekannten, bedeutendsten Heiligtümern dieser Art gehört das überregionale der Mefitis in Rossano di Vaglio $^{102}$. Im Zentrum dieser Anlage steht ebenfalls ein großer, sorgfältig gepflasterter Hof, der an einer Längsseite und den beiden Schmalseiten von Hallen oder Portiken umgeben war, hinter denen teilweise weitere Räumlichkeiten folgten. An der dem Eingang gegenüberliegenden Längsseite lag ein langgestreckter Altar (27,25 × 4,50 m), der in seinen Proportionen jenem aus dem Heiligtum des Poseidon Asphaleios nicht unähnlich ist ${ }^{103}$. Die Entstehung des Heiligtums wird in die zweite Hälfte des 4. Jahrhunderts v. Chr. gesetzt, die monumentale Ausgestaltung erfolgte am Ende des 3. oder im 2. Jahrhundert v. Chr. und entspricht damit einer regelhaft bezeugten Entwicklung für eine Reihe lukanischer Heiligtümer ${ }^{104}$.

Obwohl sich das Heiligtum der Mefitis in Rossano und jenes des Poseidon Asphaleios und der Hera in Velia aufgrund der unterschiedlichen Proportionen, aber auch der Abweichungen wegen in der Bauausführung auf den ersten Blick nur bedingt ähnlich sehen, weisen sie doch einige gemeinsame Merkmale auf, die vermutlich funktional bedingt sind. Gemeinsam ist ihnen das zentrale Element eines von Hallen umgebenen Hofs ohne Kultgebäude im griechischen Sinn, also ohne Naos, sowie die Bedeutung des langgestreckten Altars, der zweifellos das kultische Zentrum des Platzes darstellte. So deutlich das Heiligtum des Poseidon mit dem von Säulen- bzw. von Pfeilerhallen umgebenen Hof einen in dieser Zeit geläufigen griechischen Bautypus aufnimmt, so klar sind auch die Hinweise, dass den Bauherrn dieser Anlage das architektonische Bild, vielleicht aber auch die dahinter liegenden religiösen Vorstellungen zeitgleicher lukanischer Heiligtümer ${ }^{105}$ vertraut waren. Die Annahme, dass die Verbindungen Velias zum lukanischen Kulturkreis enger waren, als wir das bisher aufgrund der literarischen Überlieferung angenommen haben ${ }^{106}$, scheint somit durch die Analyse dieses Heiligtums Unterstützung zu erfahren, auch wenn viele Fragen noch zu stellen sein werden: Erfolgte die Übernahme 'lukanischer' Vorstellungen für die Verehrung eines 'griechischen' Gottes wie Poseidon Asphaleios intentionell, von lukanischen Bauherrn ausgehend und für lukanische Besucherinnen und Besucher der Stätte? Oder flossen hier - unbewusst - Vorstellungen ein, die einfach dem, was im geographischen Raum Lukanien in dieser Zeit üblich war, entsprachen, ohne dass die griechische Bevölkerung Velias dies dezidiert als ausschließlich für die Lukaner charakteristisch empfand? Welche Rolle spielt hier die singuläre Angleichung der Hera an weibliche Gottheiten lokaler Bedeutung wie Leukothea oder die Sirenen? Die hier nur zu einem Teil vorgestellten Untersuchungen am Mauerzug A haben durch die notwendige Einbeziehung der entlang der Befestigung liegenden Heiligtümer neue Perspektiven in deren Erforschung eröffnet, die diese Fragen wohl nicht alle beantworten, aber unser Bild von Velia zweifellos entscheidend bereichern werden.

Prof. Dr. Verena Gassner

Institut für Klassische Archäologie der Universität Wien, Franz Klein-Gasse 1, A-1190 Wien

E-Mail: verena.gassner@univie.ac.at

Abbildungsnachweis: Alle Abb. (C) Velia-Archiv des IKA der Universität Wien.

102 D. Adamesteanu - H. Dilthey, Macchia di Rossano. Il santuario della Mefitis. Rapporto preliminare, Quaderni di Archeologia e Storia antica 3 (1992).

${ }^{103}$ Die unsymmetrische Teilung des Altars in zwei Hälften erinnert außerdem entfernt an den Altar auf der Zeusterrasse, der als solcher zwar einheitlich scheint, neben dem sich aber ein kleinerer Sockel für Weihgeschenke (?) befindet.

104 Adamesteanu - Dilthey (Anm. 102) 78 f.; zur allgemeinen zeitlichen Entwicklung vgl. Barra Bagnasco - Russo Tagliente (Anm. 101) $183 \mathrm{f}$.

105 Vgl. z. B. Torre di Satriano: R. R. Holloway, Satrianum. The Archaeological Investigations Conducted by Brown University in 1966 and 1967 (1970); E. Greco (Hrsg.), Satriano 1987-1988. Un biennio di ricerche archeologiche (1988); M. Rosaria Salsano, Satriano, in: M. Cipriani - F. Longo (Hrsg.), Poseidonia e i Lucani. Paestum, Museo Archeologico Nazionale 27 aprile 1996 (1996) 102-103; A. Russo Tagliente, Armento. Archeologia di un centro indigeno, BA 35/36, 1995 (2000).

106 Vgl. Greco (Anm. 105). 